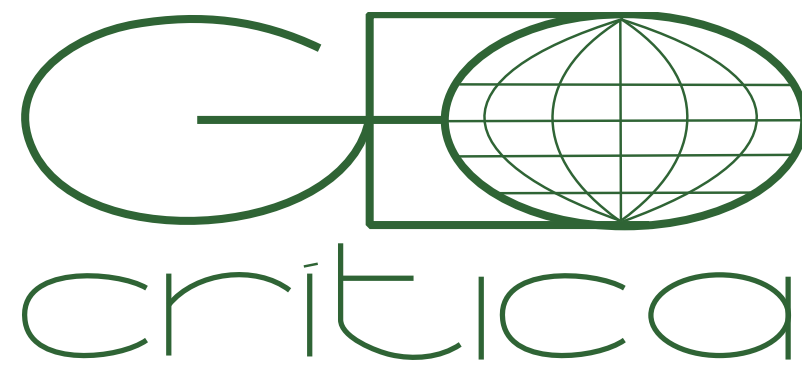

\section{Scripta Nova}

Revista Electrónica de Geografía y Ciencias Sociales Universitat de Barcelona

ISSN: $1138-9788$

Vol. 25, Núm. 2 (2021), p.75- 103

\title{
LA PRODUCCIÓN DE UN BARRIO DESFAVORECIDO EN LOS MÁRGENES DE UNA CIUDAD MEDIA: LA MARIOLA (LLEIDA)
}

\author{
Carme Bellet Sanfeliu \\ Universitat de Lleida \\ carme.bellet@udl.cat
}

Recibido: 28 septiembre 2020; Devuelto para correcciones: 13 abril 2021; Aceptado: 28 abril 2021

Esta

contribución ha

sido realizada en el marco del proyecto de investigación

"Evolución de las políticas

urbanísticas en ciudades medias españolas y sus áreas urbanas:

1979-2019 “(RTI2018096435-B-C21), financiado por el Ministerio de Ciencia,

Innovación y Universidades (España) Proyectos $\mathrm{I}+\mathrm{D}+\mathrm{i}$ en la

convocatoria

Retos

Investigación de 2018 , con fondos FEDER.

\section{La producción de un barrio desfavorecido en los márgenes de una ciudad media: La Mariola (Lleida) (Resumen)}

La Mariola es un barrio de la ciudad de Lleida que se caracteriza por la notable concentración de polígonos de vivienda. Desde mediados de siglo XX, las actuaciones públicas realizadas en materia de vivienda y suelo, primero por organismos estatales y luego autonómicos y locales, resultaron determinantes en la configuración de su estructura, forma y en su relación con el conjunto urbano. El barrio es hoy uno de los que concentra una mayor proporción de pobreza y estigmatización de la ciudad, situación que se relaciona con la acción (e inacción) de la política pública lo largo del tiempo.

El texto aborda los procesos y los mecanismos espaciales que explican la (re)producción de la condición de barrio desfavorecido en una ciudad media. Y se concluye que la combinación de ciertos mecanismos (segregación, construcción de barreras físicas y simbólicas, y producción de imágenes desvalorizantes) ha generado un espacio confinado y estigmatizado en el conjunto y notablemente fragmentado en su interior.

Palabras clave: barrio desfavorecido, polígonos de vivienda, segregación, periferia, estigmatización territorial.

\section{The creation of a deprived neighbourhood on the margins of a medium-sized city: La} Mariola (Lleida) (Abstract)

La Mariola is a neighbourhood of the city of Lleida which is characterised by a significant concentration of housing estates. The public housing and land-development actions that have been undertaken out there since the mid-20th century, first by Spain's national government and then by autonomous government and local administration, have been decisive in configuring its present structure, form and relations with the rest of the city. Today, this neighbourhood has one of the city's largest concentrations of poverty and is a stigmatised area. This has been a consequence of the long-term action (and often inaction) of public policy.

The text examines the processes and spatial mechanisms that explain the creation of a deprived neighbourhood within a medium-sized city. It goes on to conclude that the combination of certain mechanisms (such as segregation, the construction of physical and symbolic barriers, and the creation of negative images) has produced a confined and stigmatised space with a high degree of internal fragmentation.

Key words: deprived neighbourhood, housing estates, segregation, periphery, territorial stigmatisation. 
La Mariola, con sus 11.440 habitantes, es uno de los barrios más poblados y densos de Lleida, una ciudad media de 139.315 (Padrón Municipal de Habitantes 2019) en el poniente catalán. El barrio surgió de la construcción intensiva de polígonos de vivienda pública durante el franquismo construidos en el margen y al margen de la ciudad, lejos de lo que entonces era el núcleo urbano central. En esos momentos, nacieron en la ciudad otros barrios obreros periféricos, algunos incluso más alejados que la Mariola y creados a través de procesos de urbanización marginal, como el Secà de Sant Pere y Magraners (Vilagrasa 2003) (Fig.1). Sin embargo, ninguno de esos barrios concentra actualmente la pobreza, la marginalidad y el estigma territorial de la Mariola.

Lo que nos interesa en el presente texto es entender cómo y porqué el barrio de la Mariola ha sido asociado, desde su origen, a la marginalidad, cuáles son los procesos y los factores que habrían incidido en la construcción (física, social y simbólica) de ese espacio como periferia y cuáles son aquellos que han contribuido a su mantenimiento como tal. Más concretamente, nos interesa analizar los procesos y los elementos espaciales que explican la producción y la reproducción de la marginalidad y estigma a lo largo del tiempo. Se trataría así de revelar los mecanismos espaciales que contribuyen a la concentración, y posterior confinamiento, de una población altamente estigmatizada con el objetivo de neutralizar la posible amenaza material y/o simbólica que esa población y barrio puede representar para algunas otras personas y grupos sociales (Delgado 2014).

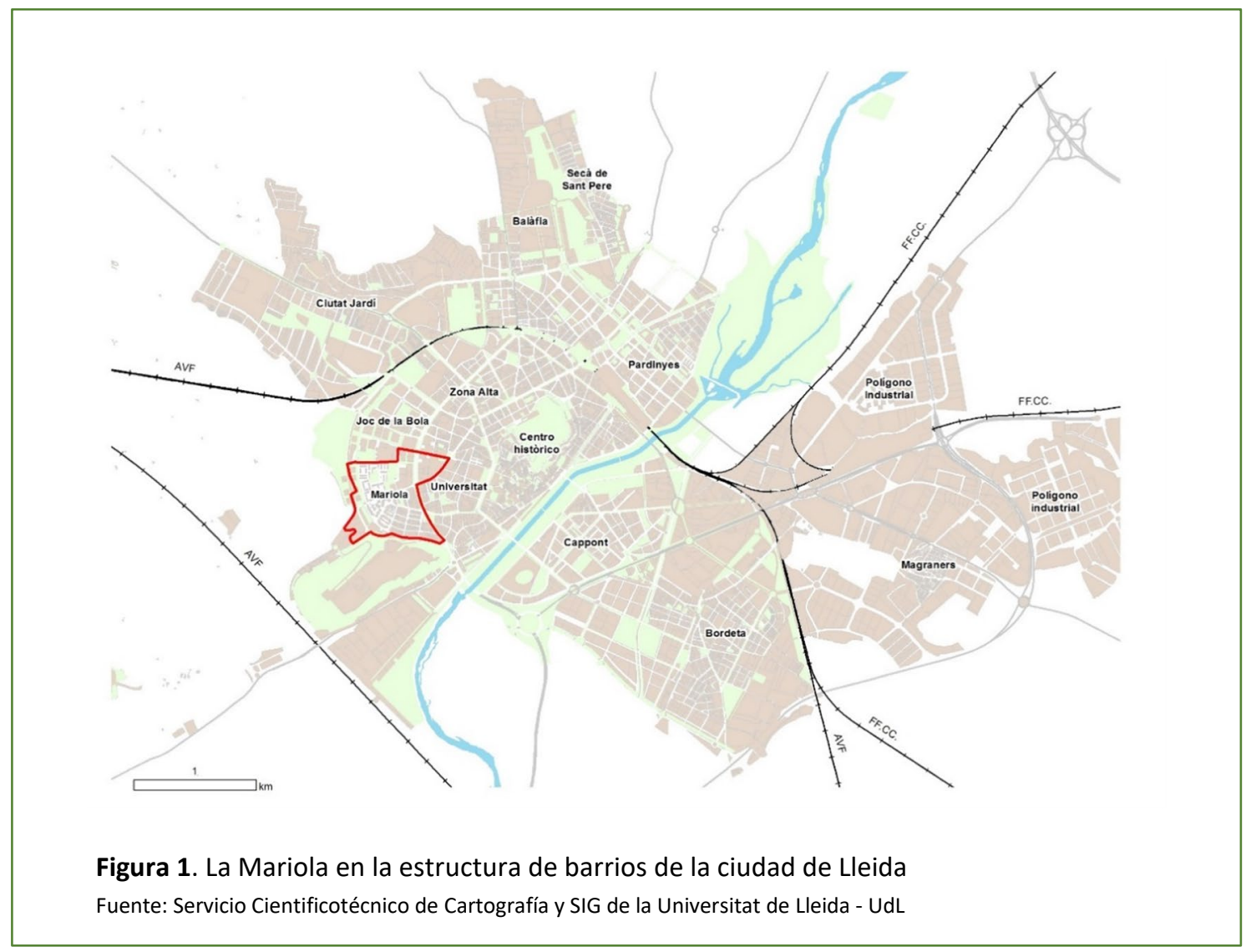

Aquello que se lee como marginal, se produce en las periferias que no son centrales en términos socioespaciales y funcionales (López Sánchez 2015). En la medida que un lugar periférico pueda adquirir la condición de central deben de producirse o reproducirse 
mecanismos para, o bien mantener su condición como periferia (a través de la vigilancia, control y contención), o bien transformarla a través de otros mecanismos si este lugar adquiere interés para ser centralizado, pudiéndose desplegar entonces mecanismos de desplazamiento de ciertos usos y grupos sociales (García Herrera 2018).

De entre los mecanismos espaciales de mantenimiento de la condición de periferia de la Mariola, destacamos aquí los siguientes: los procesos de segregación espacial (concentración de la población), la producción de barreras físicas y simbólicas que delimitan y confinan a la población (contención) y la estigmatización territorial (neutralización de la población). Mediante el uso y despliegue de estos mecanismos, se produce el manejo de la pobreza que Wacquant calificaría de punitivo (Wacquant 2007b).

\section{La producción de la periferia, marginalidad y el estigma territorial en una ciudad media}

Etimológicamente barrio viene del termino árabe hispánico barr que significa exterior, cuya forma bárri, se refiere a aquello que se encuentra fuera de las murallas. El exterior, el afuera de la ciudad, es el significado que viene a recoger el termino barrio en castellano. A su vez, los vocablos del árabe hispánico provienen de barrī, que, en árabe clásico significa salvaje.

Así, el barrio, en su doble condición de periférico y salvaje, viene definido por su otredad y por su oposición creada y nombrada desde una posición central. Esa condición de periferia (López Sánchez 2015), al margen de la ciudad y al margen del sistema, caracteriza aún a muchos de los barrios desfavorecidos de nuestras ciudades que concentran notables dosis de pobreza y situaciones de vulnerabilidad (Alguacil 2006; Alguacil et al. 2014).

En el marco de la aplicación de las políticas neoliberales, y el fomento de los principios capitalistas de competencia y acumulación, se habrían ampliado la desigualdad social, la pobreza y la violencia que tenderían a concentrarse en espacios de relegación y de no derecho en nuestras ciudades. La cuestión de la segregación socioespacial (residencial, educacional, sanitaria, en la salut, etc.) es cada vez más relevante como irregularidad espacial que reproduce y agrava las desigualdades sociales existentes y profundiza en la injusticia espacial (Lehman-Frisch 2009; Soja 2014). Unos procesos de segregación que ya no podrían leerse tanto en términos verticales, explotadores-explotados (utilizando la terminología marxista), como más horizontales y en términos de dentro-fuera del sistema (Sassen 2015). Procesos de expulsión que, en lugares determinados, derivarían en espacios de exclusión donde se concentra aquello que es desechado por la sociedad postindustrial (Castel 1995).

La desigualdad y la segregación que los barrios desfavorecidos espacializan como periferia en oposición a un/os centros (funcionales y simbólicos), resulta muy didáctica. La existencia y mantenimiento de la periferia se convierte en una distancia simbólica (más que física o social) que amenaza con el descenso social a aquellos que no se esfuercen lo suficiente, alimenta el deseo de ascenso social de quienes viven en ella y atrapa dentro a quien no estuvo a la altura de las circunstancias (Ávila y García 2007).

En un contexto de dualización, polarización y fragmentación social, resulta muy tentador aplicar directamente esas visiones a lo espacial: la ciudad dual, la ciudad polarizada, 
o la ciudad fragmentada (Wacquant 2007a). Las metáforas son didácticas, y, si bien contribuyen a explicar los extremos (la ciudad de los ricos y la ciudad de los pobres), tienden a invisibilizar las situaciones intermedias y la situación de pobreza creciente entre muchas de las familias de los tradicionales barrios obreros y de clase media (Marcuse 1989; Van Kempen 2007), hoy en clara descomposición. El aumento de la pobreza habría avanzado espacialmente en un proceso de segregación en el que convive y se articula la segregación socioespacial horizontal con la vertical. Por un lado, la segregación horizontal tomaría formas más extremas en unos pocos barrios y áreas urbanas, mientras que, por otro, la segregación vertical (en algunas viviendas de un mismo edificio, en algunos edificios) afectaría a barrios tradicionalmente de rentas medias de una forma más dispersa.

Una ciudad en la que la relación entre proximidad y accesibilidad habría cambiado radicalmente. La proximidad ya no implicaría que se compartan espacios o se realicen actividades y usos en común, ya que, en caso de compartirse, se haría con principios o con formas diferentes. Los lugares de encuentro universal son cada vez menos frecuentes y el principio de exclusividad es el que rige la producción y el consumo de los nuevos productos urbanos (residenciales, espacios de consumo y espacios públicos). Así, los espacios y actividades exclusivas pueden coexistir (que no convivir) junto con los espacios de y para la exclusión en la ciudad privativa contemporánea (Bellet 2007).

En las últimas décadas, ha proliferado un buen número de términos en medios académicos, políticos y de comunicación, para referirse a este tipo de barrios que son entendidos como barrios problema ${ }^{1}$ : barrios vulnerables, barrios desfavorecidos, barrios marginales, o guetos. Serían los territorios en los que tiende a concentrarse lo que Wacquant identifica como la marginalidad avanzada: "los nuevos desechos sociales que, en lugar de repartirse por el conjunto de los antiguos barrios obreros, se aíslan y encierran en unos pocos barrios, percibidos cada día más, tanto por fuera como por dentro, como los purgatorios sociales de la ciudad postindustrial" (Wacquant 2007a,194)

En el texto, utilizamos el termino barrio desfavorecido (Alguacil 2006) frente a otros posibles, porque nos interesa recalcar el papel de la producción social del espacio como uno de los enfoques explicativos de los procesos de segregación urbana (Capel 1999). Entendemos que el termino desfavorecido contribuye mejor a la comprensión del proceso al ponerlo en relación a unas agencias (alguien y algo ha provocado/incidido, voluntaria o involuntariamente, en ese proceso) y ello ocurre en relación a otros lugares (ese lugar es desfavorecido respecto a otros barrios). Afrontar las problemáticas de los barrios desfavorecidos implicaría, así, abordar tanto cuestiones del propio barrio como las cuestiones estructurales de desigualdad y segregación que han conducido a esa situación en un contexto determinado (Massey y Fischer 2000).

La proliferación de barrios desfavorecidos en las ciudades europeas viene a mostrar la descomposición social de los territorios obreros, resultante del efecto conjunto de la desindustrialización, la precarización del trabajo y el progresivo desmantelamiento del Estado y las políticas de bienestar. En estos barrios, se acumulan los expulsados de la ciudad

1 Es decir, no se trata de un barrio con problemas, sinó que la propia existencia del mismo es vista como problemática. 
postindustrial (jóvenes y personas en paro, jóvenes nini, drogadictos, personas sin hogar, inmigrantes sin papeles y etnias minoritarias) (Wacquant 2007b).

A las políticas públicas ya no les competería reducir la desigualdad, sino organizar los mecanismos y dispositivos necesarios para la detección, contención y control de aquellas situaciones que podrían desembocar en fenómenos disruptivos y potencialmente peligrosas para el resto. De esta manera, se produciría un desplazamiento de la cuestión de la desigualdad y la distancia social, que ya no requeriría de distancia espacial, hacia la cuestión de la seguridad y la gestión del miedo (Beck 2008). El despliegue de los dispositivos securitarios y del control social del miedo permitirían: "canalizar las ansiedades de un malestar social complejo hacia colectivos visibles y diferenciados hasta reducirlas a un simple miedo a la criminalidad y la incivilidad, evitando así el cuestionamiento de la violencia estructural y de las relaciones de poder - económicas, políticas, de género, etc. - que la engendran" (Ávila y García 2015, 88).

La política pública habría renunciado a los mecanismos de redistribución de recursos y rentas para centrarse en la gestión y el control de la desigualdad, ya que: "las desigualdades sociales no son sino palanca del deseo y estímulo de la rivalidad y la competencia, auténticos motores de lo social" (Ávila y García 2007, 88). Estas personas y grupos marginalizados encarnan y recuerdan, especialmente a las clases medias, la situación de inseguridad generalizada fruto de los cambios socioeconómicos recientes (Beck 2008).

Por último, señalamos las cuestiones diferenciales que la condición de barrio desfavorecido en una ciudad media plantea, como es nuestro caso, introduciendo los factores de escala, tamaño y estructura urbana. Lleida es una ciudad media de 139.315 habitantes (Padrón Municipal de Habitantes 2019) que actúa como centro de servicios y equipamientos en el amplio llano del poniente catalán caracterizado por su notable especialización en el sector agroindustrial. Se trata además de un municipio cuya mayoría de población se concentra en el núcleo urbano central que ha logrado mantenerse relativamente compacto, continuo y denso (Fig. 1).

La condición de ciudad media, con una estructura y forma compacta, explica, en primer lugar, que se establezca una relación mucho más directa de los diferentes barrios con el modelo y las dinámicas del conjunto (Bellet y Llop 2004). En segundo lugar, esas mismas características contribuyen a que los mapas sociales y mentales sean bien definidos y más fácilmente aprehendidos por la población (Aguilar y Bellet 2016). Así, puede identificarse con mayor facilidad la espacialidad de las jerarquías sociales, especialmente la de los extremos. En tercer lugar, la distancia social que podría existir, no encuentra su equivalente en la distancia física y espacial entre los grupos, como podría darse en otro tipo de ciudades de mayor tamaño y con una estructura menos compacta. De hecho y paradójicamente, en Lleida, las rentas medias-altas y altas de la ciudad (en buena parte concentradas en Ciutat Jardí, Vila Montcada y Joc de la Bola) se encuentran localizadas, como veremos, inmediatas al barrio objeto de estudio (Fig.1). Por ello mismo, en estas circunstancias y en este tipo de ciudades, pasarían a operar con mayor fuerza otros mecanismos de control y de distanciamiento de entre los que podemos destacar los siguientes: primero, los de tipo urbanístico (barreras de equipamientos y espacios verdes, barreras funcionales, 
infraestructuras de transporte y vías de alta capacidad) y arquitectónico (tipo y ordenación de los edificios); y, segundo, los de tipo simbólico (narrativas denigrantes, mapas mentales jerarquizados, estigma territorial). Estos mecanismos se muestran tanto o más efectivos que la propia distancia física, ya que implican la contención y la neutralización de la población de los barrios desfavorecidos.

\section{La marginalidad al margen. La producción de un espacio periférico en la periferia del poniente catalán (1941-1990)}

La Mariola se caracteriza morfológicamente por la concentración de polígonos de vivienda social pública que fueron construidos por iniciativa pública, entre 1941 y 1974, en el margen oeste de la ciudad de Lleida (Bellet y Módol 2006).

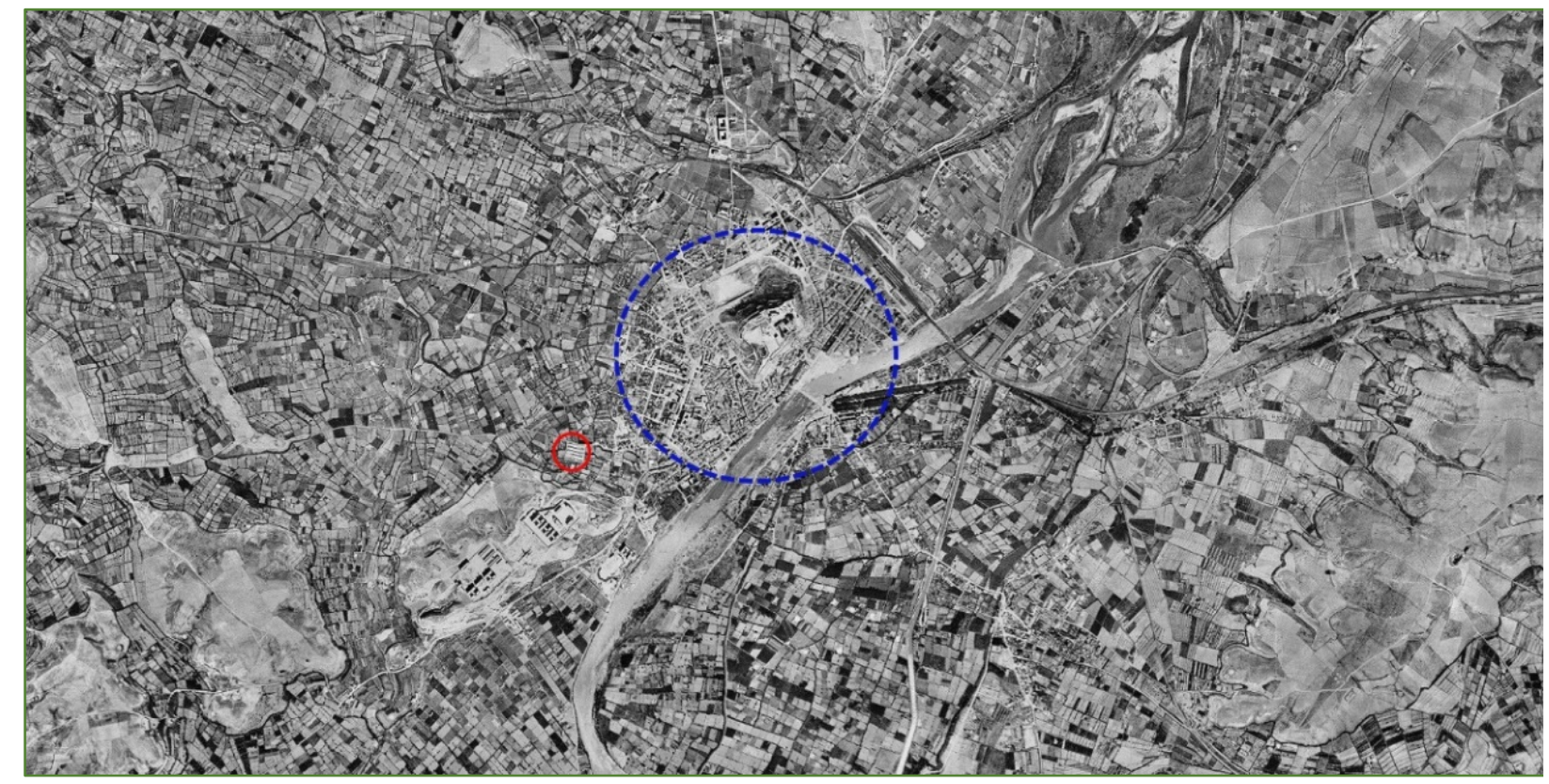

Figura 2. La localización de la primera promoción de viviendas en la Mariola: grupo Ruiz de Alda Fuente: Realización propia sobre imagen aérea del Institut Cartogràfic i Geològic de Catalunya, ICGC - Vuelo de 1946.

Nota: La línea azul rodea el área urbana consolidada, la roja la localización de la primera promoción de viviendas que da origen, en 1941, al barrio.

El desarrollo urbanístico del barrio se inicia en 1941, cuando la Obra Sindical del Hogar (OSH) realiza su primera intervención en la ciudad con la construcción del grupo Ruiz de Alda con 100 viviendas. El grupo se construye, en aquel entonces, en la periferia y muy lejos del centro urbano, sobre una antigua partida rural que da nombre al barrio (Fig. 2).

Las viviendas, con una superficie de $53 \mathrm{~m} 2$, se disponen en edificios de baja altura de dos plantas. La arquitectura y tipología es de estilo ruralista como el de las Casas Baratas de postguerra (Fig. 4). Estas viviendas, localizadas cerca de la meseta de Gardeny (Fig.3), donde se estaban construyendo los nuevos cuarteles militares (Base Gaspar de Portolá), fueron en buena parte ocupadas por familias de militares y cuadros funcionariales medios. 


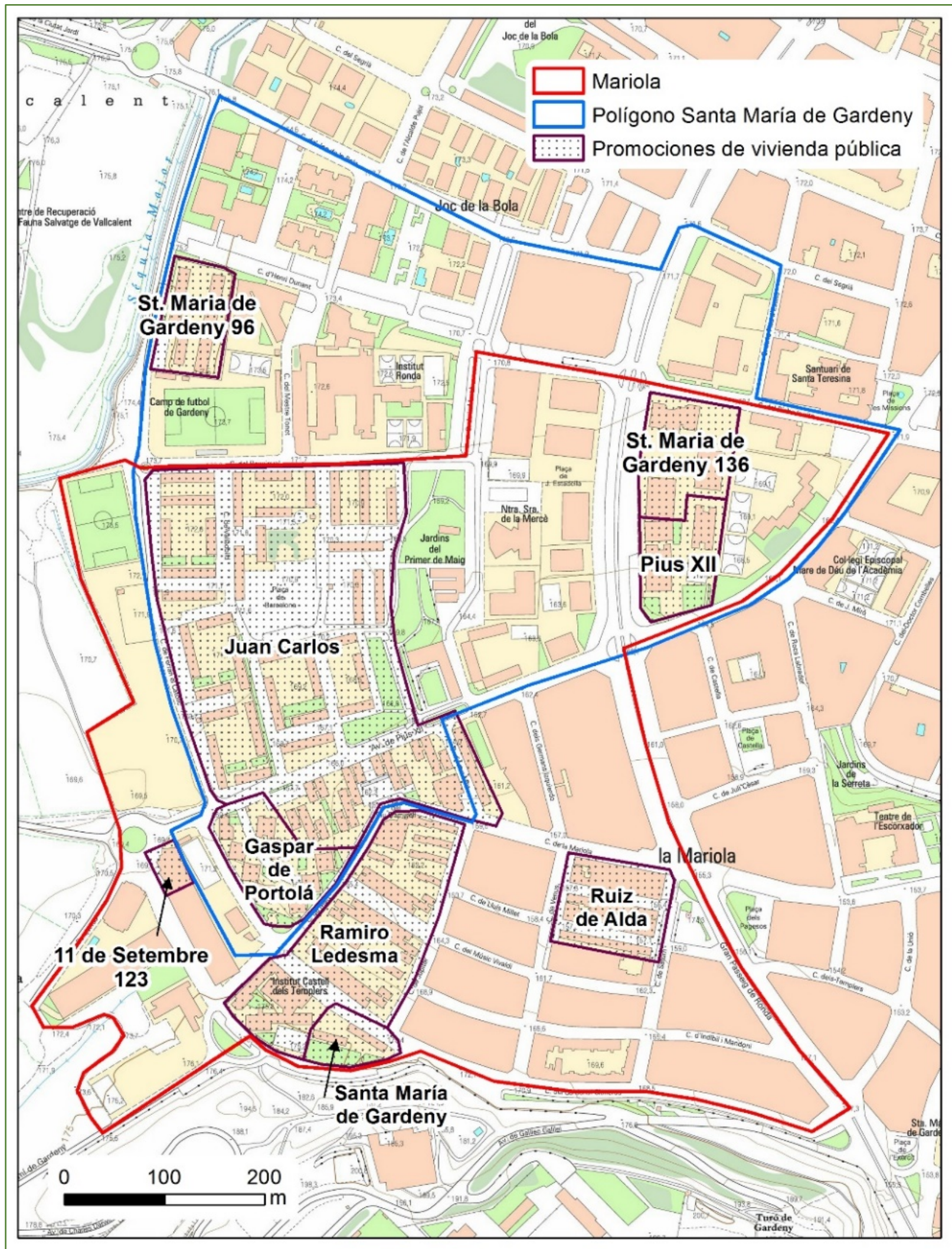

Figura 3. Las promociones de vivienda social pública en la Mariola (Lleida)

Fuente: Servicio Cientificotécnico de Cartografía y SIG de la Universitat de Lleida 
Cuadro 1. Grupos de vivienda social promovidos por organismos públicos en la Mariola²

\begin{tabular}{|c|c|c|c|c|c|}
\hline Promoción & $\begin{array}{c}\text { Año } \\
\text { Construcción }\end{array}$ & Promotor & $\begin{array}{c}\mathrm{N}^{\mathbf{0}} \\
\text { viviendas }\end{array}$ & Sup. Mín & Sup. Máx \\
\hline Ruiz de Alda & 1941 & Obra Sindical del Hogar & 100 & 52,69 & 52,96 \\
\hline $\begin{array}{l}\text { Ramiro Ledesma I } \\
\text { (hoy Grupo Mariola) }\end{array}$ & 1954 & Obra Sindical del Hogar & 206 & 33,14 & 34,86 \\
\hline $\begin{array}{l}\text { Ramiro Ledesma II } \\
\text { (hoy Grupo Mariola) }\end{array}$ & 1957 & Obra Sindical del Hogar & 262 & 41,41 & 41,54 \\
\hline $\begin{array}{l}\text { Santa María de } \\
\text { Gardeny (hoy } \\
\text { Cardenal Cisneros) }\end{array}$ & 1960 & Obra Sindical del Hogar & 50 & 45,33 & 55,78 \\
\hline Gaspar de Portolá & 1969 & Obra Sindical del Hogar & 152 & 69,52 & 82,72 \\
\hline Bloques Juan Carlos & $1972-1974$ & $\begin{array}{c}\text { Obra Sindical del Hogar } \\
\text { - INV }\end{array}$ & 904 & 46,71 & 82,23 \\
\hline Pius XII & 1979 & $\begin{array}{c}\text { Instituto Nacional de la } \\
\text { Vivienda - INV }\end{array}$ & 136 & 49,81 & 74,86 \\
\hline $\begin{array}{l}\text { Santa María de } \\
\text { Gardeny } 136\end{array}$ & 1980 & INV-Generalitat & 136 & 49,81 & 74,86 \\
\hline 11 de Setembre, 123 & 2010 & $\begin{array}{c}\text { Agència Catalana de } \\
\text { l'Habitatge - } \\
\text { Generalitat de } \\
\text { Catalunya }\end{array}$ & 52 & 61 & 92 \\
\hline Total & & & 1.998 & & \\
\hline
\end{tabular}

Fuente: Realización propia a partir de trabajo de trabajo de archivo (ADIGSA, Archivo Municipal de Lleida y Catastro)

A mediados de los años cincuenta el mismo organismo, la OSH, procedería a la construcción de un nuevo grupo compuesto por 468 viviendas: el grupo Ramiro Ledesma (hoy Grupo Mariola). El grupo fue construido en dos fases desplegadas entre 1954 y 1960. La primera de las fases, a unos 300 metros al oeste de Ruiz de Alda, genera un amplio vacío intersticial (Fig. 3). Se trata de bloques lineales, de 4-5 plantas que contienen viviendas con una superficie de entre 40,9 a $50 \mathrm{~m}^{2}$, muy pequeñas para alojar familias extensas. El proyecto inicial contemplaba, además, la construcción de escuela, comercios e iglesia, aunque finalmente sólo se construyeron el equipamiento educativo y la iglesia. Los bloques, pese a conservar aún algunos elementos del estilo ruralista inicial (el uso de la teja, el tejado a dos aguas, la forma de los portales, etc.), van realizando la transición estilística hacía los nuevos lenguajes de la arquitectura racionalista (Fig. 5).

2 En 1981, se aprobaría la construcción de un grupo para 96 viviendas justo al otro lado del limite norte del barrio: Santa María de Gardeny 96. La nueva promoción quedaría adscrita al barrio Joc de la Bola, en el que predominan las rentas medias-altas. Compuesta de bloques de baja altura, los edificios se disponen alrededor de un patio central abierto y ajardinado que otorga cierta calidad al conjunto. 


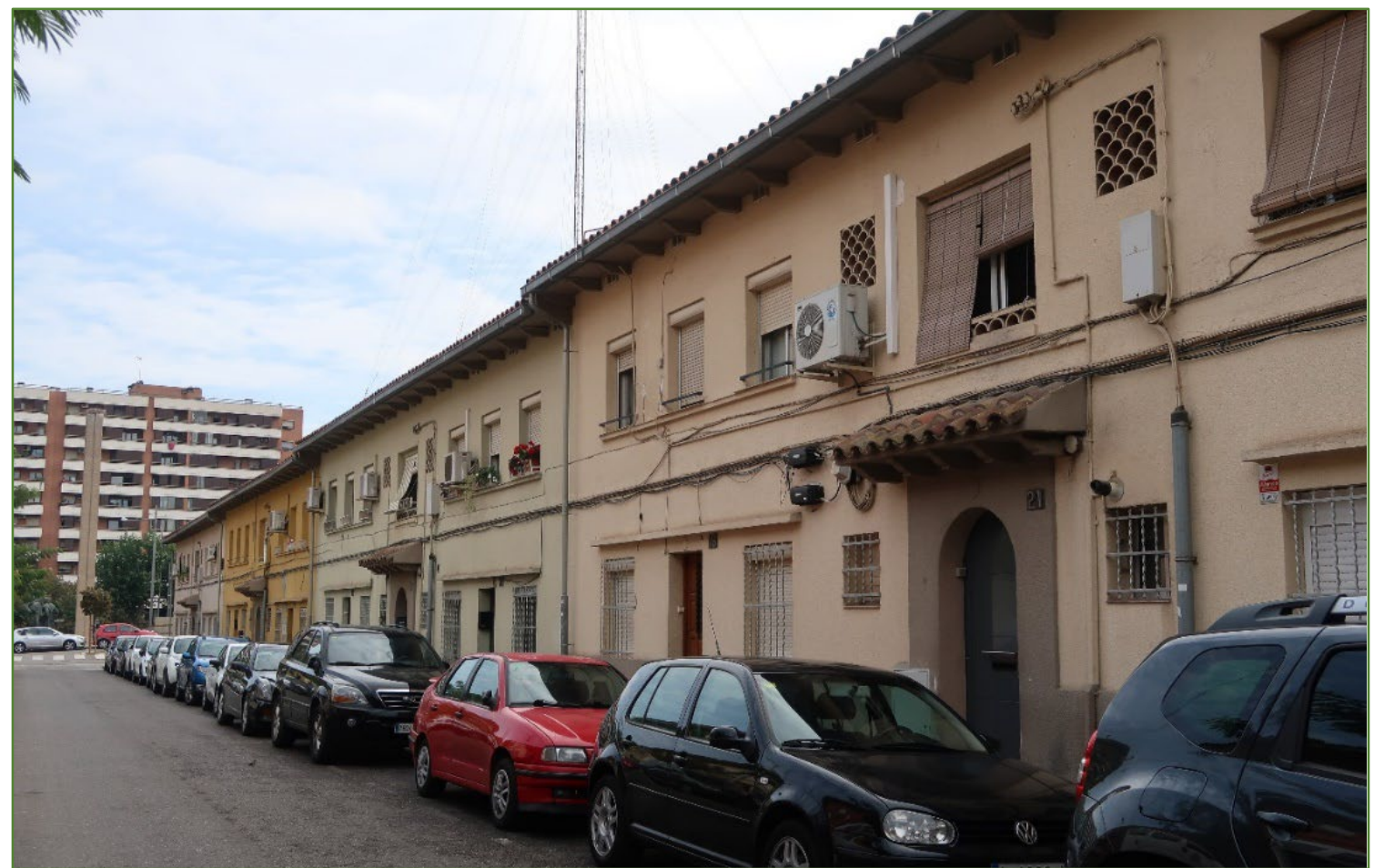

Figura 4. Fotografía actual del grupo Ruiz de Alda en la Mariola

Fuente: fotografía de la autora

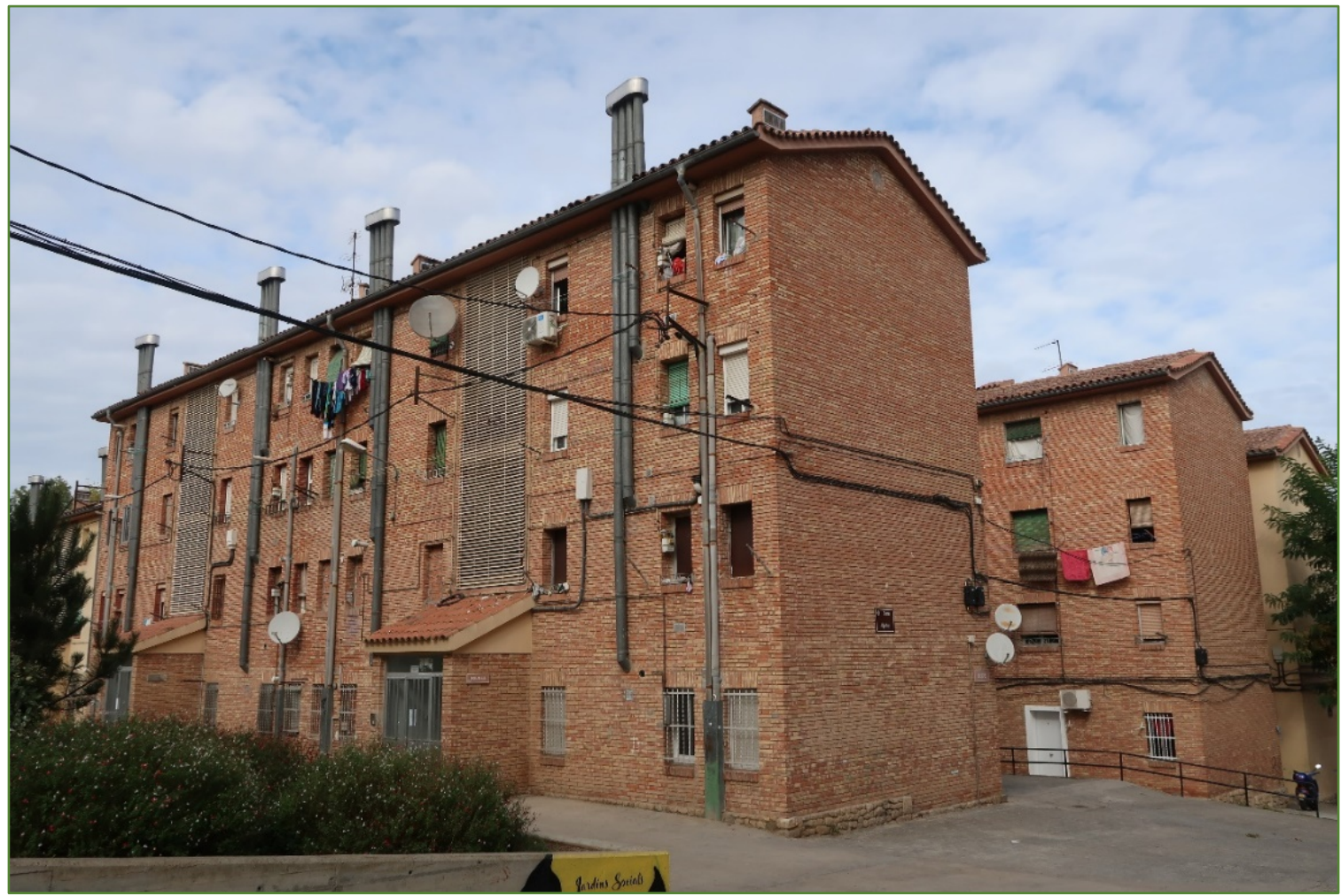

Figura 5. Bloques de la fase 1 de Ramiro Ledesma, hoy grupo Mariola Fuente: fotografía de la autora 
En 1960 y justo al lado de la fase 2 de Ramiro Ledesma, se aprueba la construcción de otras 50 viviendas, el grupo Santa María de Gardeny (hoy Cardenal Cisneros), realizado de nuevo por la OSH (Fig.3). Se trata de la construcción de bloques lineales de 5 plantas con dos tipos de vivienda con superficies que van de los 54,9 a los $64,9 \mathrm{~m}^{2}$. Junto a los bloques que cierran el área poligonal al oeste, se construye en 1961 la primera escuela del barrio: Magí Morera. La escuela y la iglesia serán los únicos equipamientos con que contará el barrio hasta mediados de la década de los setenta.

Los nuevos polígonos del grupo Cardenal Cisneros acogieron población de bajos recursos procedente del Centro Histórico de la ciudad y familias recién llegadas de Andalucía, Extremadura, Castilla y León y Murcia, entre otros (Solís 2017).

Estas tres promociones residenciales de la OSH, realizadas entre 1941 y 1960, dan origen al barrio de la Mariola y dejan al sur-sureste una amplia área intersticial que la iniciativa privada irá colmatando lentamente después. La parte sur y sureste del barrio toma forma de ensanche con manzanas cerradas por la construcción de bloques de baja altura derivando en la configuración de una área obrera, densa y compacta, con pocos espacios libres y menos equipamientos. A diferencia del área poligonal, ésta cuenta con locales comerciales generando la posibilidad de que, en los bajos, se alojen actividades económicas que dotan servicios al conjunto del barrio.

En 1963, el Instituto Nacional de Urbanización inicia la expropiación de suelo en esta área de la ciudad para su posterior urbanización. El Polígono Residencial recibe el nombre de Santa María de Gardeny y cuenta con una superficie de $469.287 \mathrm{~m}^{2}$. Para su desarrollo y ordenación, se aprueba en 1963 el Plan Parcial que preveía la construcción de 4.626 viviendas en polígonos de vivienda con una densidad resultante de cerca de $100 \mathrm{viv} / \mathrm{Ha}$ (Fig.6). La aparición de la nueva ley del Suelo de 1975 conlleva la revisión del Plan Parcial cuyas modificaciones se aprobarían en 1976. La reforma del Plan Parcial se dirige, por una parte, a la reducción del número de viviendas, pasando de las 4.626 iniciales a las 2.608 finales; $y$, por otra, al aumento de las dotaciones de espacios libres y equipamientos públicos (Fig. 7).

La reforma del Plan Parcial de 1976 vendría a ampliar los principios de segregación espacial que se habían ido configurando en la ciudad desde los años de postguerra. La nueva ordenación concibe las primeras barreras físicas (este y norte) que separarán las áreas de polígonos de vivienda pública de las nuevas áreas residenciales que se construirán una vez urbanizado el eje del Passeig de Ronda (Fig.12). Se consolidará primero, una barrera de equipamientos en el este del barrio, que separa el área poligonal de la fachada residencial que se construye en Passeig de Ronda y que se dirige a rentas medias. Así mismo se fijará una segunda barrera en el norte, constituida por una amplia franja de equipamientos que separa, a su vez, el área poligonal de vivienda de un nuevo barrio residencial que ya, en los años 90, se dirigirá a rentas medias-altas: el barrio Joc de la Bola (Fig. 7 y 12). 


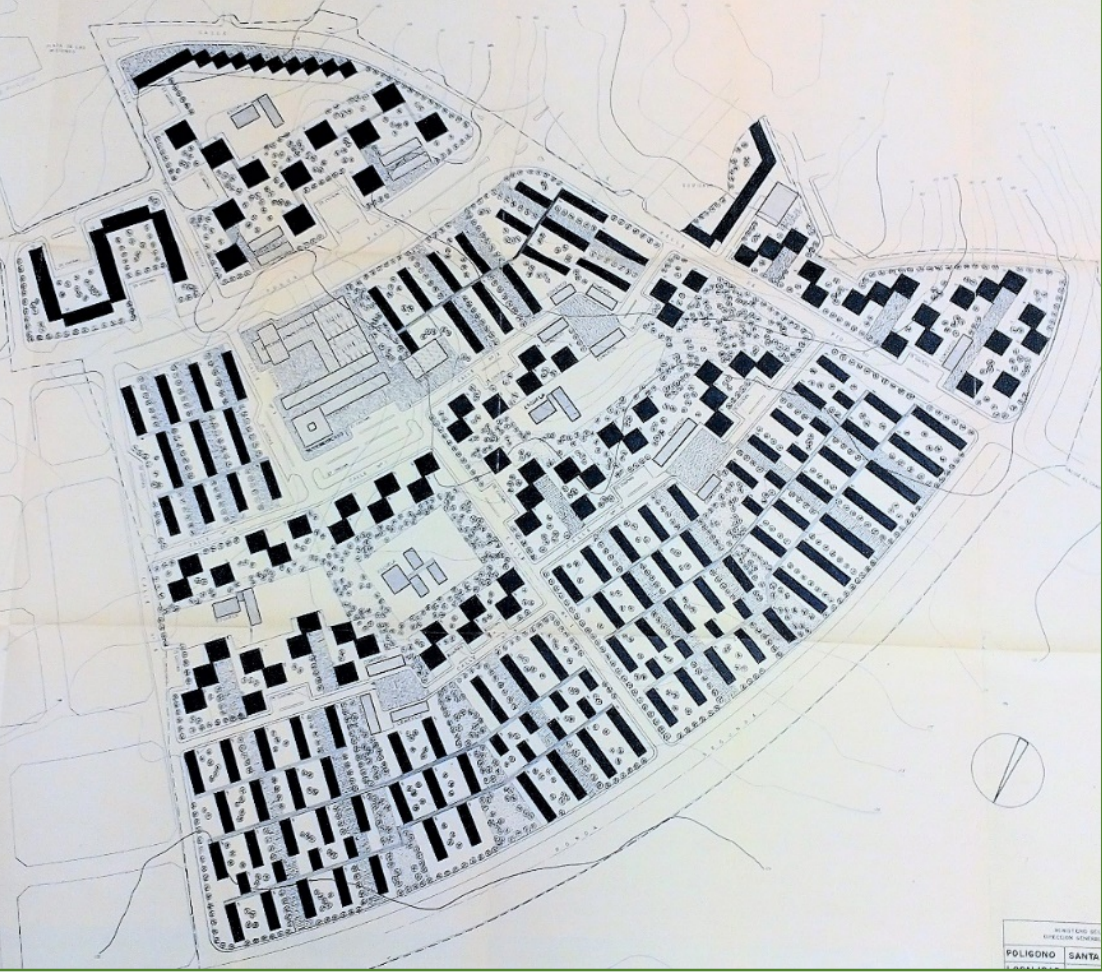

Figura 6. Plan Parcial del Polígono Santa María de Gardeny (1963)

Fuente: Documentación del Archivo Municipal de Lleida. La Paeria

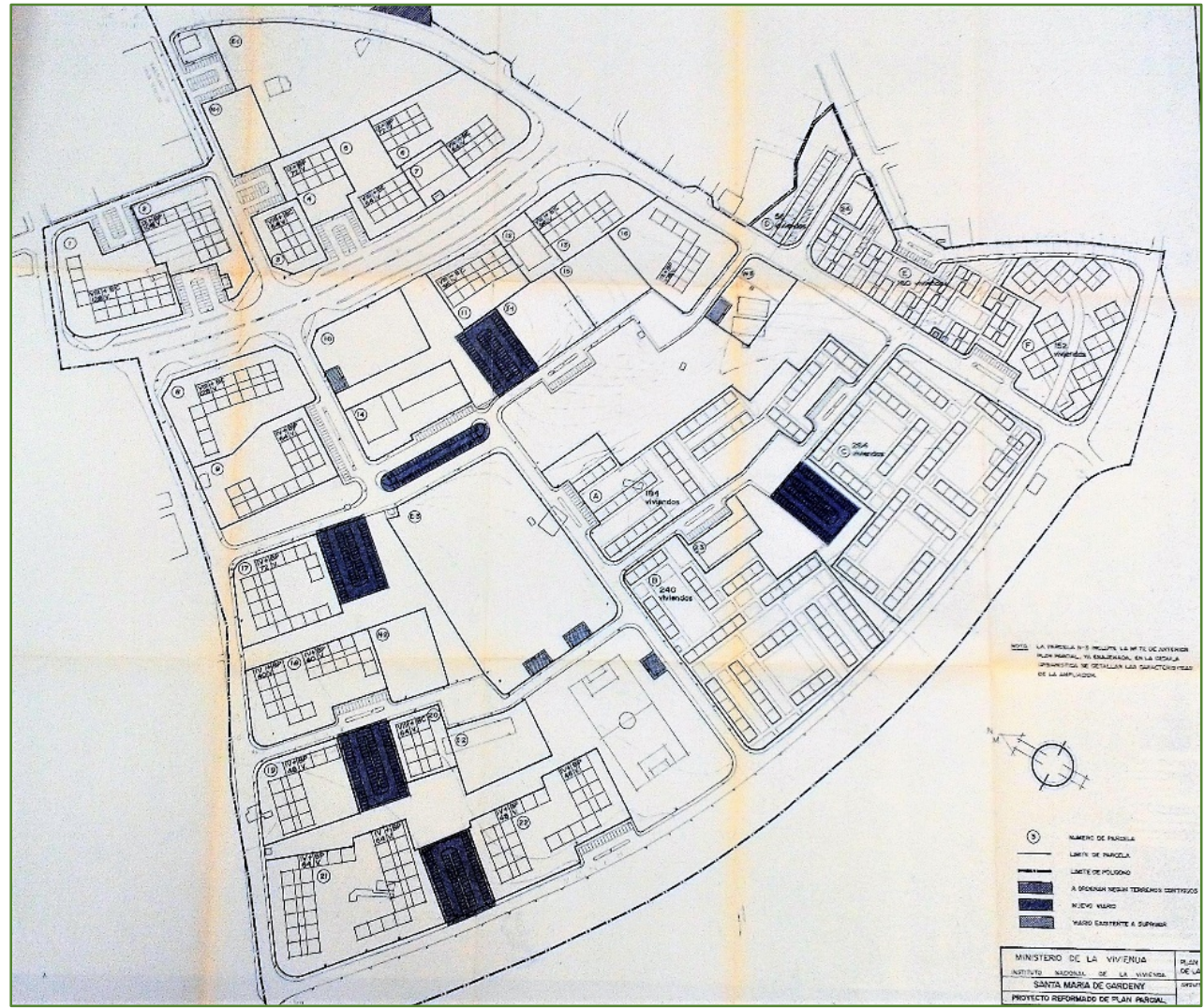

Figura 7. Reforma del Plan Parcial del Polígono Santa María de Gardeny (1976) Fuente: Documentación del Archivo Municipal de Lleida. La Paeria 
Mientras, el área del Polígono de Santa María de Gardeny se va completando con nuevos polígonos de vivienda pública. En 1969, se inicia la construcción del grupo Gaspar de Portolá que consta de 8 bloques de 4 y 5 plantas. Sus 152 viviendas tienen superficies que van de los 62,4 a los 74,2 $\mathrm{m}^{2}$. Como ya ocurriera con el proyecto del grupo Mariola, sólo se construyeron las viviendas, quedando sin consolidar el edificio comercial y la urbanización inicialmente previstos. La ordenación de los bloques Gaspar de Portolá adopta ya plenamente la ordenación abierta y su tipología responde a los preceptos de la arquitectura moderna (Fig.8).

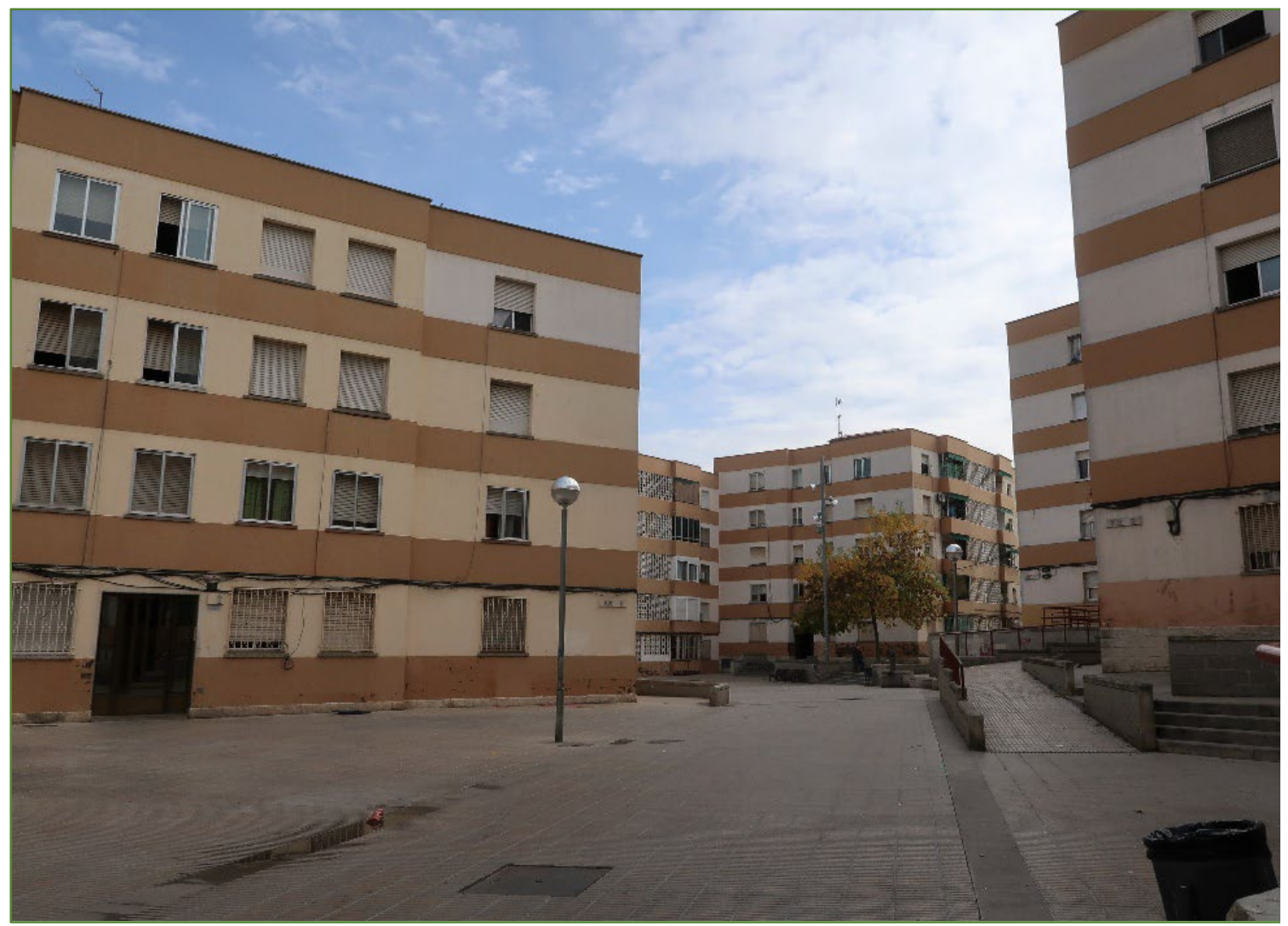

Figura 8. Los bloques Gaspar de Portolá en la actualidad Fuente: fotografía de la autora.

Entre 1972 y 1977, se construye, junto a Gaspar de Portolá, el nuevo grupo: los bloques Juan Carlos, iniciados por la OSH y finalizados por el Instituto Nacional de la Vivienda (INV). El nuevo grupo poligonal aportará 904 viviendas (sobre un área de $21.894 \mathrm{~m}^{2}$ ), la mayor promoción inmobiliaria unitaria jamás realizada en la ciudad hasta la actualidad (Fig. 9 y 10). 


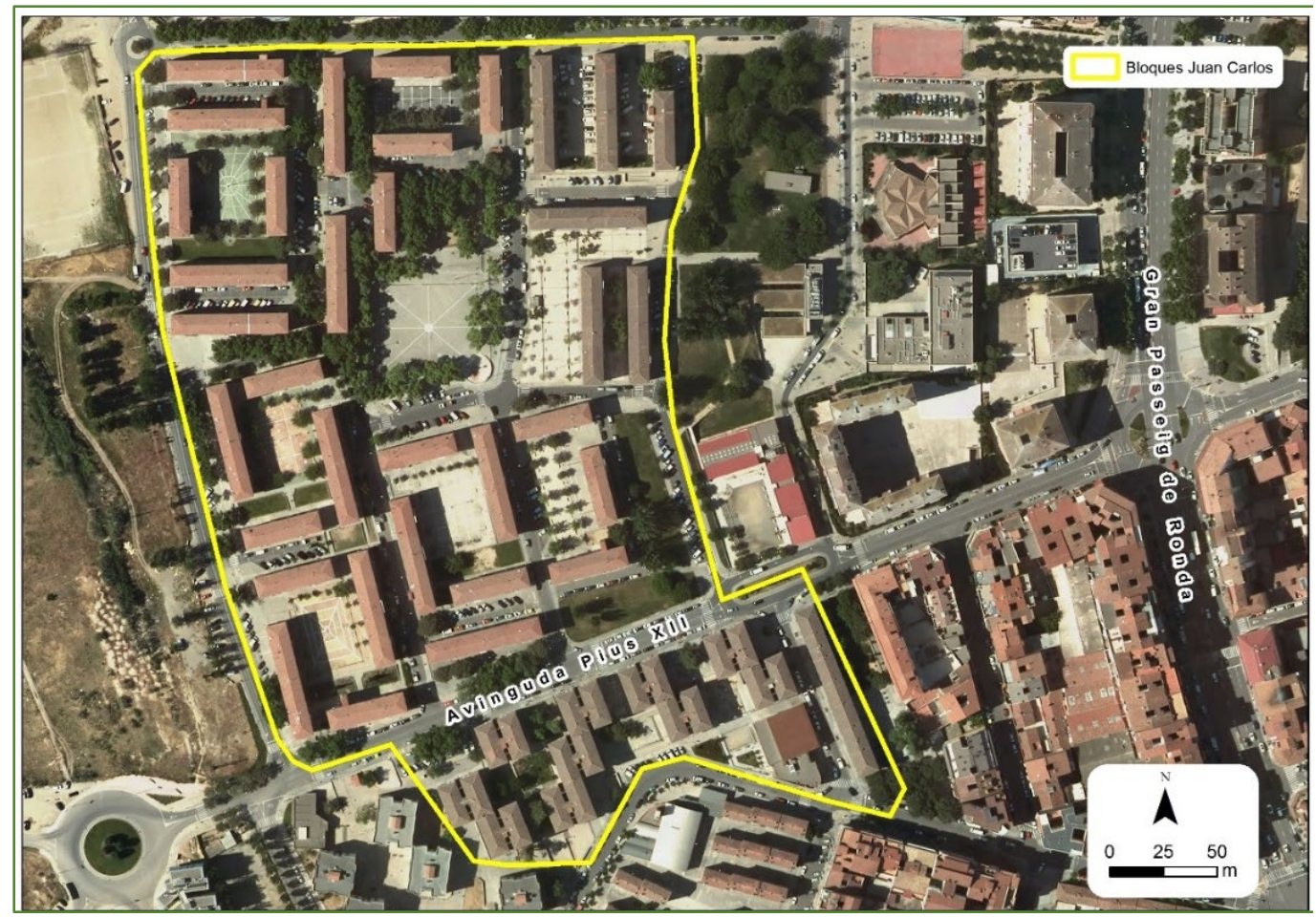

Figura 9. Imagen aérea de los bloques Juan Carlos en la Mariola

Fuente: Realización propia a partir de imagen del Institut Cartogràfic i Geològic de Catalunya - ICGC

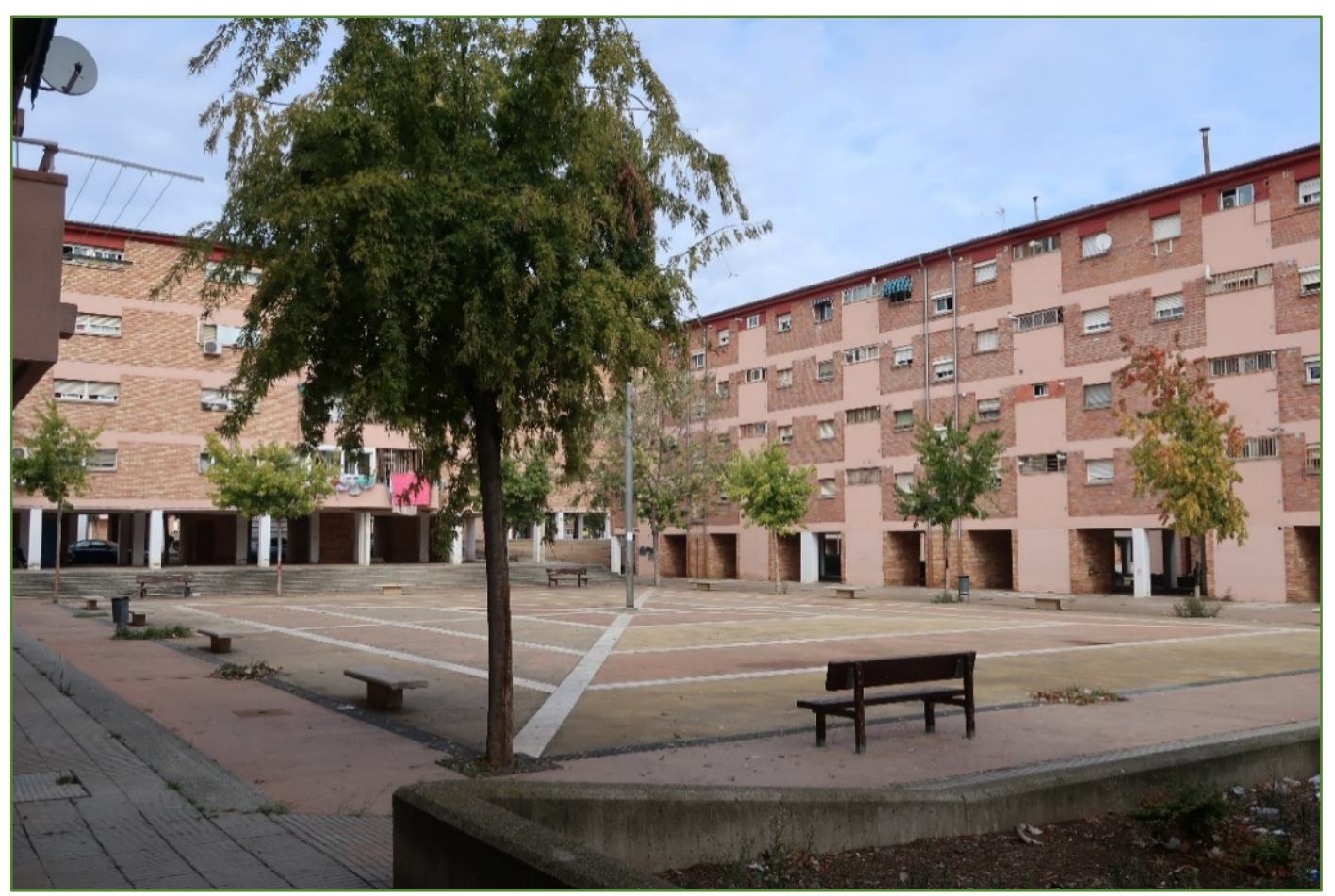

Figura 10. Los bloques Juan Carlos en la actualidad Fuente: fotografía de la autora 
Los edificios lineales se disponen en 45 bloques, cada cuatro de los cuales se orientan hacía un patio abierto interior. Se trata de bloques de cuatro plantas que liberan la planta baja, elevada por pilotes, con viviendas que tienen entre los 40 a los $72 \mathrm{~m}^{2}$ de superficie.

El proyecto preveía, inicialmente, la urbanización del conjunto, la habilitación de una gran plaza central, una escuela, patios y espacios de juego infantil, así como la construcción de 20 locales comerciales en edificios exentos. Sin embargo, poco más se construyó más allá de las viviendas. La escuela (Santa María de Gardeny) no se terminó hasta 1977 y las áreas y los patios interiores no fueron urbanizados hasta 1990-1994, ya por ADIGSA después del traspaso del patrimonio de suelo y vivienda pública del Estado a la Generalitat de Catalunya en 1981. La urbanización interbloques de mediados de los años noventa resultó en un conjunto de plazas duras con poca vegetación, escaso mobiliario e insuficiente iluminación.

Así, las tempranas intervenciones que en materia de vivienda y suelo fueron realizadas por organismos públicos, entre 1941 y 1974, resultaron en un área bastante densa de polígonos de vivienda, con escasa diversidad de usos y funciones más allá de los residenciales, una urbanización inexistente y unos equipamientos escasos y básicos que, en general, llegaron tarde.

En 1969, y de forma paralela a la construcción de los bloques Juan Carlos, se urbaniza el eje viario que, situado al este del barrio, actúa como límite administrativo de la Mariola (Fig. 12). El Passeig de Ronda es una de las vías urbanas con mayor volumen de tráfico y, además, una de las más importantes de la ciudad (N-230), cuyo entorno se construye densamente a principios de los años setenta. Como ya ocurrió en el sur del barrio, las viviendas de esta parte al este del área poligonal se dirigirían a rentas medias. El Passeig de Ronda, y su muralla edificada a ambos lados, acaba por constituirse en otra barrera física y, especialmente, simbólica que separa el barrio del resto del ensanche. A esta barrera, se le irán añadiendo otras a medida que el barrio va siendo integrado por la urbanización de los espacios intersticiales $\mathrm{y}$, en particular, a medida que la promoción inmobiliaria va consolidando el área residencial situada al norte para rentas medias-altas (Joc de la Bola).

\section{La re-producción de la marginalidad en un área cada vez menos periférica}

La necesidad de vivienda era acuciante en la ciudad después de la Guerra Civil con el notable crecimiento demográfico de los años 60, alimentado especialmente por los movimientos migratorios intrapeninsulares ${ }^{3}$.

Las intervenciones que en materia de vivienda y suelo despliegan, como hemos visto, los organismos estatales en la Mariola alivian débilmente unas necesidades que el mercado tampoco estaba preparado para paliar (Vilagrasa 2002). El crecimiento de postguerra va lentamente produciendo una nueva estructura urbana dual en un doble plano social y espacial: un núcleo central y un nuevo ensanche a su alrededor en el que se concentra la población autóctona y una periferia obrera en los nuevos barrios que irá acogiendo la población recién llegada y las familias más pobres (Vilagrasa 1990).

3 La ciudad pasa de 41.464 habitantes en 1940 a 90.884 en 1970 (Censos de Población- INE). 
La Mariola es un lugar cargado de memoria acumulada de pobreza cuya periferización y marginalización se reproduce una y otra vez. Parte de la población que originalmente alojaron los grupos Ramiro Ledesma (Grupo Mariola), Gaspar de Portolá y Juan Carlos provenía de un asentamiento muy precario de barracas de cañas y barro de 3,5 hectáreas, el Canyeret. Esta área se fue consolidando desde el siglo XVIII y tras la Guerra de Sucesión, en la ladera sur de la meseta central que había sido militarizada en pleno Centro Histórico. Tras los bombardeos de la Guerra Civil, el Canyeret queda muy maltrecho. En 1964, con la inminente amenaza de ruina Regiones Devastadas inicia la actuación "derribo constructivo", y traslada a la población que todavía residía en la zona al recinto de la antigua prisión provincial que se alzaba en pleno centro urbano (Barrull et al 2003). Con el derribo de la prisión, en 1967, la población allí hacinada es trasladada de nuevo a otro espacio más periférico: la Mariola. Se extirpa así la pobreza del centro para ser trasladada a los pies de otra meseta, la de Gardeny, más periférica y colonizada también por la nueva caserna militar construida a partir de 1945 para liberar la catedral medieval (la Seu) de los usos militares ${ }^{4}$. Pobreza y marginalidad, se desplazan paradójicamente junto con el ejercito del centro a la periferia, de una meseta central en el Centro Histórico (coronada por la Seu), a otra periférica (Gardeny).

Sobre el suelo recién expropiado del Polígono de Santa María de Gardeny, se irán instalando, a partir de 1967, 1.000 barracas prefabricadas de madera provenientes, en su mayor parte, del Vallès Occidental donde alojaron allí a las familias afectadas por las inundaciones de 1962. Las barracas, conocidas popularmente como les Casetes $^{5}$, fueron instaladas en el Polígono para alojar de forma provisional a las famílias que procedían de la antigua prisión y del Canyeret, a las que se fueron añadiendo otras familias de escasos recursos recién llegadas a la ciudad (Aguayo 2018). De entre sus residentes, destaca un numeroso grupo caracterizado de población gitana.

Les Casetes era también conocido en la ciudad como el Poblado del Oeste, buena metáfora para referirse a un área llena de barracas sobre $10.000 \mathrm{~m}^{2} \sin$ asfaltar, con servicios y equipamientos urbanos muy limitados, si existentes, y que llegó a alojar hasta unas 5.000 personas en condiciones muy precarias. Hacinamiento, humedad, insalubridad, problemas en el suministro eléctrico e incendios, formaban parte de lo cotidiano. Las barracas se iban desmontando a medida que iba finalizando la construcción de las viviendas de los grupos Gaspar de Portolá y Juan Carlos procediendo de manera paulatina al realojo de la población. Así, lo que iba a ser un alojamiento provisional se convirtió en una realidad que duró hasta 10 años: 1947-1977.

\footnotetext{
4 La base militar Gaspar de Portolá se queda sin uso y cierra en 1995. El área es adquirida por la Paeria, en 1998, y más tarde, en 2005, convertido en un Parque Cientifico y Tecnológico, gracias a un consorcio entre la Universitat de Lleida y el consistorio local.

5 Las barracas contenían viviendas de entre 50 a $65 \mathrm{~m}^{2}$ con las características siguientes: "estructura metálica tubular, cubierta de placas de fibrocemento onduladas (uralita); tabiquería interior con paneles de madera, unidos con moldura de recercado; entarimado sobre viguería de madera que reposa en jácenas de hormigón". Proyecto de desmontaje, transporte y montaje de 500 albergues provisionales tipo AIO de Tarrasa (Barcelona) a Lérida. INV. Archivo Histórico de Lleida.
} 
En les Casetes, nace una de las primeras y más reivindicativas Asociación de Vecinos de la ciudad, en plena dictadura en julio de 1970. La Asociación canaliza las demandas de los vecinos y alienta la autoorganización vecinal, generando no pocas tensiones con los organismos locales y estatales (Barrull et al 2003; Aguayo 2018).

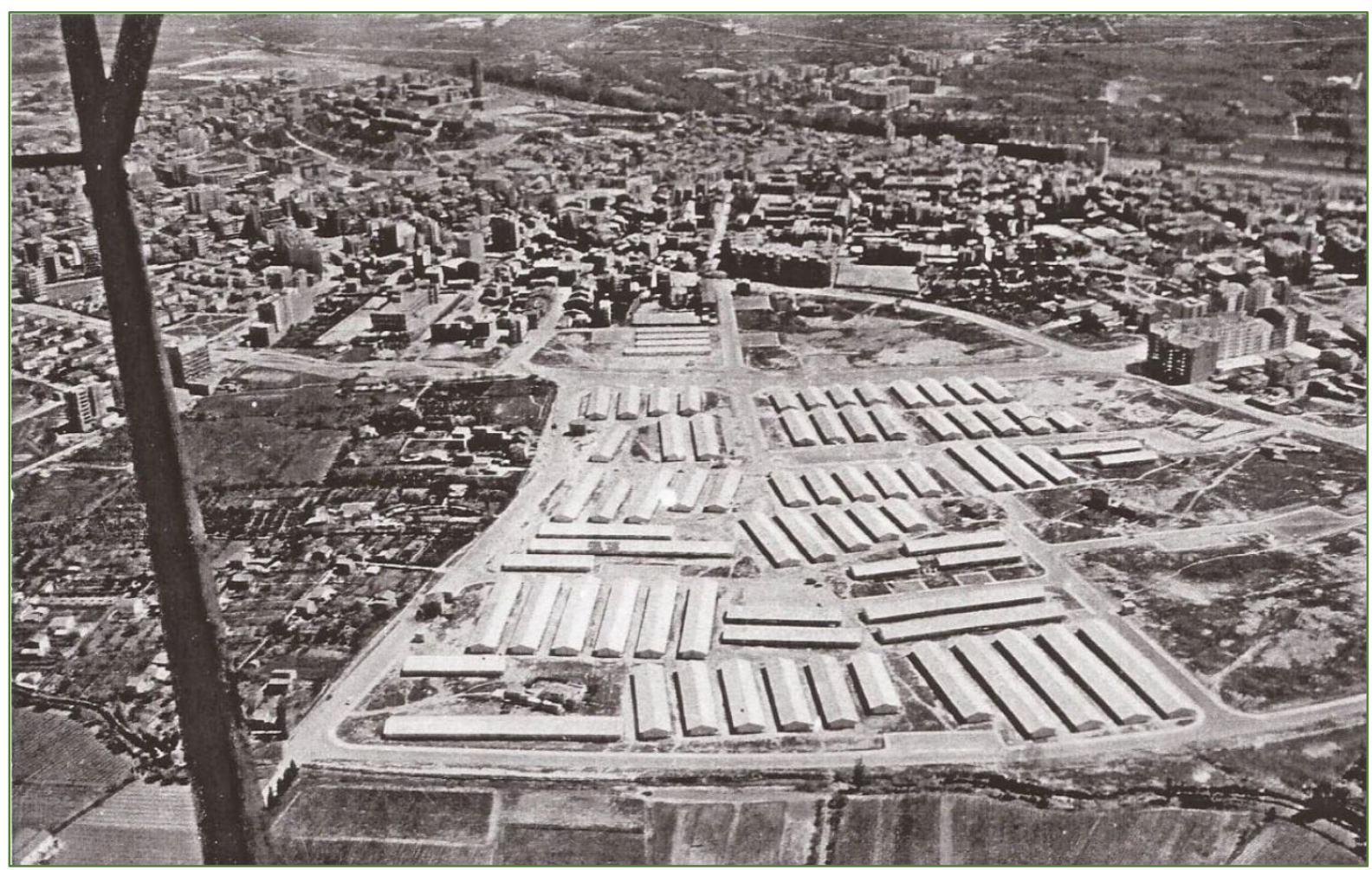

Figura 11. Vista aérea del asentamiento Les Casetes (1947-1977) en el Polígono Santa María de Gardeny Fuente: Instituto Nacional de la Vivienda. Información sobre los polígonos de Santa María de Gardeny, el Segre y Cañeret, solicitada por la Inspección General. Archivo Histórico de Lleida.

Tras la dictadura, a principios de los años 80 y poco antes de efectuar el traspaso del patrimonio en materia de suelo a la Generalitat, el INV subasta las parcelas restantes no edificadas del Polígono de Santa María de Gardeny. Las primeras parcelas subastadas al este son adquiridas por la Cooperativa de la Sagrada Familia que promueve, a mediados de los ochenta, 558 viviendas destinadas a rentas medias 6 . Sin embargo, las parcelas del norte son adquiridas, en su práctica mayoría, por promotores profesionales locales que, dada su proximidad con Ciutat Jardí, dónde se estaban empezando a ubicar las rentas altas de la ciudad, orientarán la producción inmobiliaria de esta zona a las rentas medias-altas. A finales de los años 80, se presentan varios Estudios de Detalle para la ordenación de esta área norte del antiguo Polígono, donde se va reforzando la barrera de equipamientos ya predefinida en la reforma del Plan Parcial de 1976 (Fig. 7) (Bellet 1995). La barrera del norte se refuerza con una amplia y arbolada vía, que transcurre paralela a la barrera de equipamientos (Fig.

6 Al frente de la Cooperativa figura Rufino Gómez del Castillo, funcionario de la Obra Sindical del Hogar (Vilagrasa 1990). 
12). La calle Henri Dunant, es la divisoria de dos secciones de distrito (y dos barrios) con rentas medias familiares muy diferentes: 15.716 euros es la renta media de la sección 4.10 en la Mariola (donde se encuentran los bloques Juan Carlos) y 49.770 euros la renta media de la sección 5.6 al norte y ya en el barrio de Joc de la Bola, siendo de 30.713 euros la del conjunto de la ciudad (INE 2016) (ver Cuadro 2 y Fig. 12).

Por si la barrera de equipamientos (formada por los equipamientos siguientes: Escuela Pública+Instituto de Educación Secundaria+Cruz Roja+Centro social+ Campo de

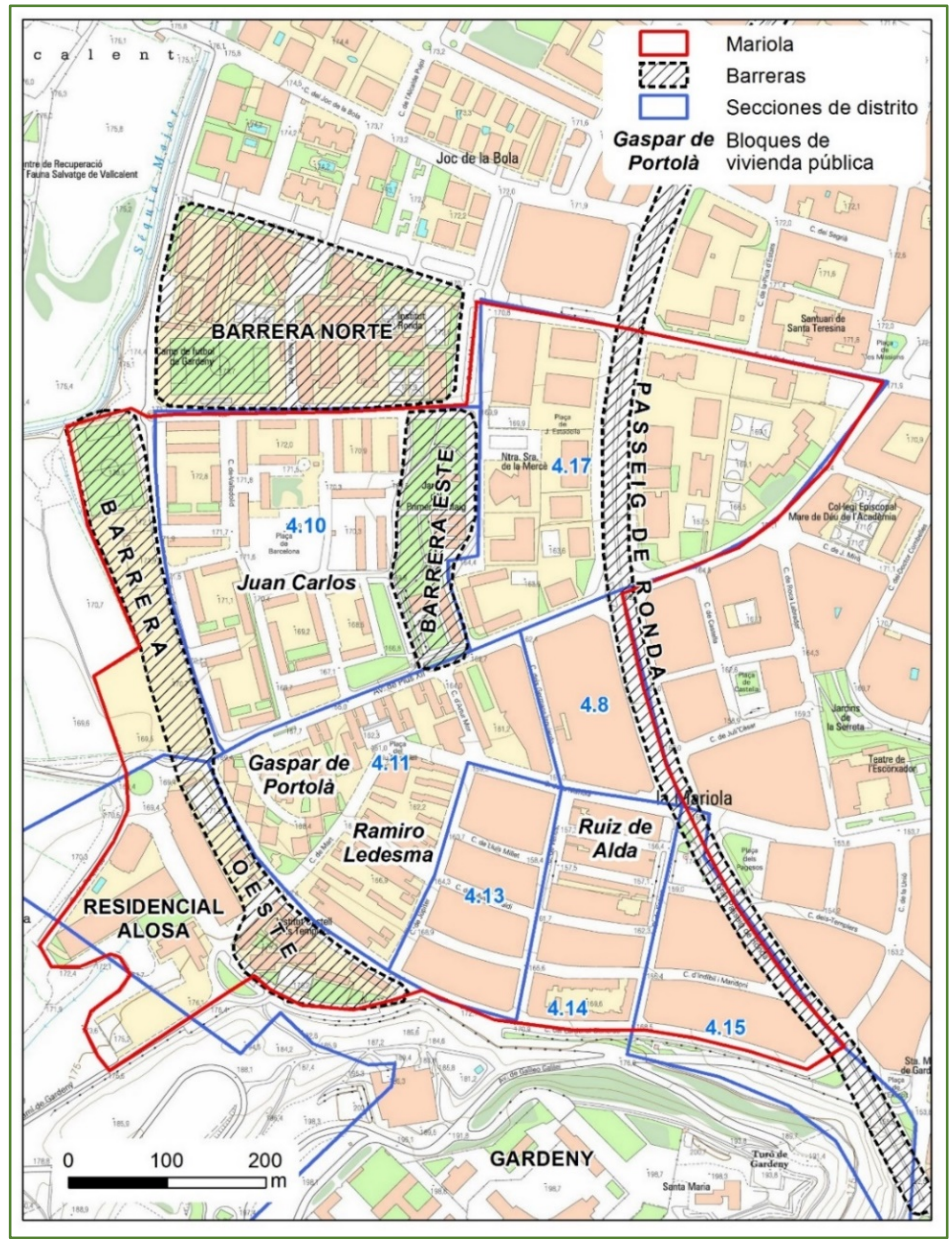

Figura 12. Barreras físicas y simbólicas en la Mariola y sus alrededores Fuente: Servicio científico-técnico de Cartografía y SIG de la Universitat de Lleida. Las secciones de distrito censales reflejadas en el mapa son las existentes en 2016, año para el que se ofrecen los datos de renta en el presente texto.

Futbol) y el eje viario (calle Henri Dunant) que divide los dos barrios no fueran suficientes, las nuevas promociones dirigidas a las rentas medias-altas en Joc de la Bola escenifican, en el lugar, su distinción a través del lenguaje de la arquitectura privativa que despliegan los enclaves residenciales (Bellet 2007). Las diferentes promociones se encuentran delimitadas por muros y vallas, de una forma más simbólica que física dada la altura de las mismas. Los muros escenifican la arquitectura del control del medio: en la accesibilidad, en los usos y en el gobierno de la comunidad. La distinción se despliega también dentro de las promociones con servicios y espacios libres exclusivos para la comunidad (siendo las zonas ajardinadas y las piscinas, lo más común), aunque limitados en número y en superficie. 
La construcción de estos enclaves privativos en Joc de la Bola se desarrolla, en su mayoría, en los años noventa, una década muy difícil para la Mariola. El barrio entra en una espiral de reproducción de pobreza y marginalidad con la progresiva huida de las rentas medias hacía otros barrios y lugares de la ciudad y su substitución por familias con menos recursos (Fig.14). Después de llegar a mediados de los años ochenta a su máximo poblacional (unos 15.000 hab.), empieza a producirse un cierto declive en los años noventa, cuando "se hacen visibles las drogas, tanto en su consumo como su venta, también los rumores sobre delincuencia y gamberrismo toman fuerza y, finalmente, la continua llegada de población pobre a través de la movilidad forzada (desalojos de otros lugares)" (Solís 2017, 60). Todo ello, se fue sumando a una progresiva debilitación de los lazos fuertes y de las relaciones vecinales intensas creadas desde la formación inicial del barrio (Corona 2019).

El proceso de descomposición social que vive el barrio se acelera con la política de realojamiento del consistorio local. Uno de los procesos de realojamiento más complejos se da entre 1992 y 1999 cuando se procede a la ubicación en el barrio de tres diferentes clanes de familias de etnia gitana que son trasladadas desde un campamento que se había ido formado cerca del río Segre en el oeste de la ciudad. El realojo de las familias en el área poligonal produce no pocas confrontaciones de las personas ya residentes con el Ayuntamiento. El nuevo contingente viene a sumarse a los grupos de etnia gitana que ya, desde el origen, se habían asentado en el barrio, de forma que la población de dicho colectivo podría representar hoy entre un 50-60\% del conjunto de población del área poligonal (Gutiérrez y Paul 2011), aunque con una notable heterogeneidad (Corona 2019).

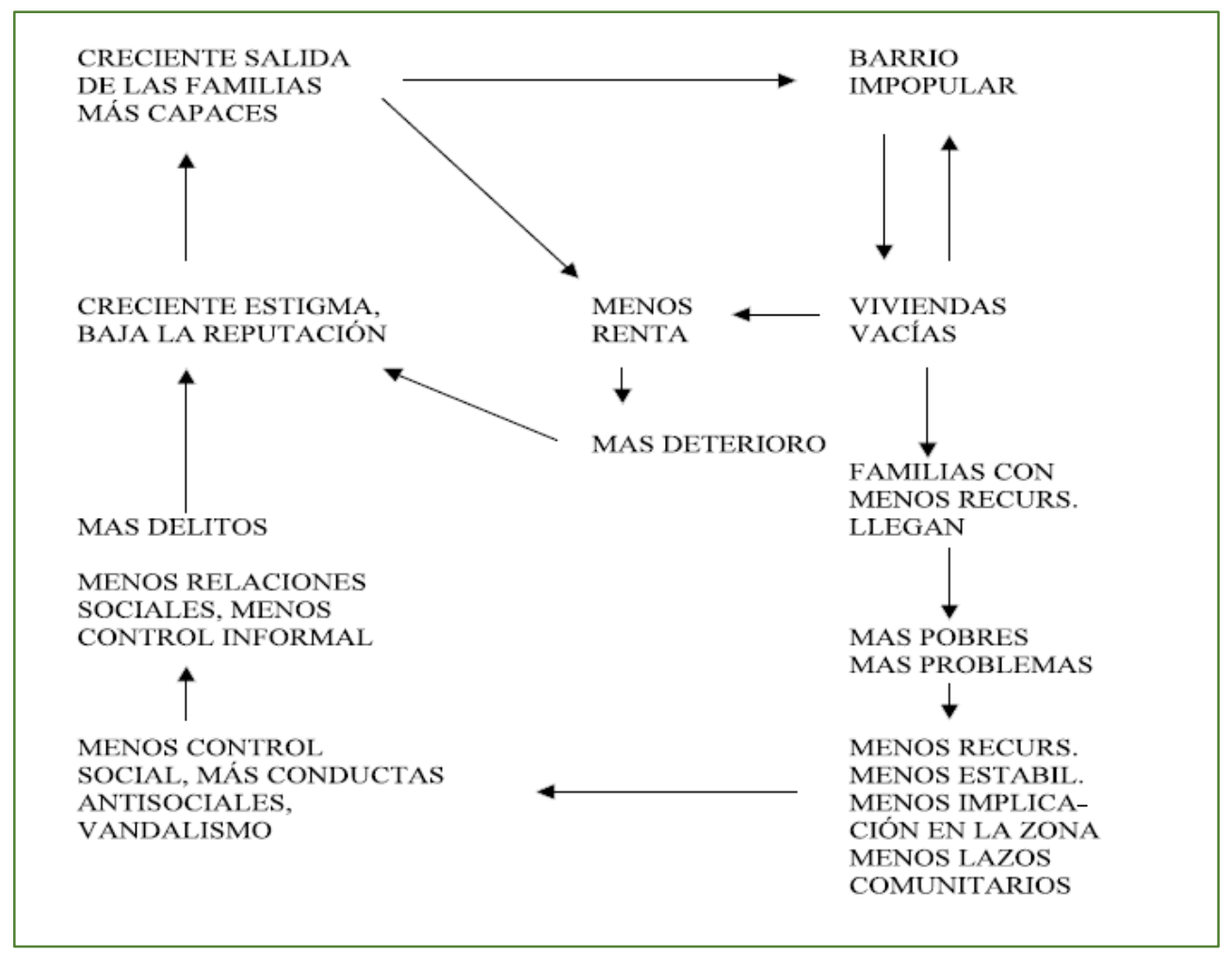

Figura 13. El circulo de la vulnerabilidad territorial

Fuente: Subirats, J. et al. (2004) Institut de Govern i Polítiques Públiques - IGOP 
Los cambios sociodemográficos se incrementan con la llegada al barrio y a la ciudad de población extranjera, bastante intensa entre finales de los años 1990 y la década de los 2000. La población foránea pasa de representar en el barrio el 0,3\% en 1991 (0,5\% en la ciudad) al 21,6\% en 2018 (19\% en la ciudad) ${ }^{7}$, notablemente concentrada en el sur y en el este del barrio. Muchas de las nuevas familias recién llegadas adquieren las viviendas en propiedad, en un momento de crédito fácil y barato, aprovechando también los bajos precios de la vivienda en el lugar (Méndez 2018). Así pues, flujos de población y flujos de capital, como hemos visto intensivos en los años 2000, dejan al barrio y a su población en una situación de mayor vulnerabilidad, que se agrava con la llegada de la crisis de 2008 (Fig.14).

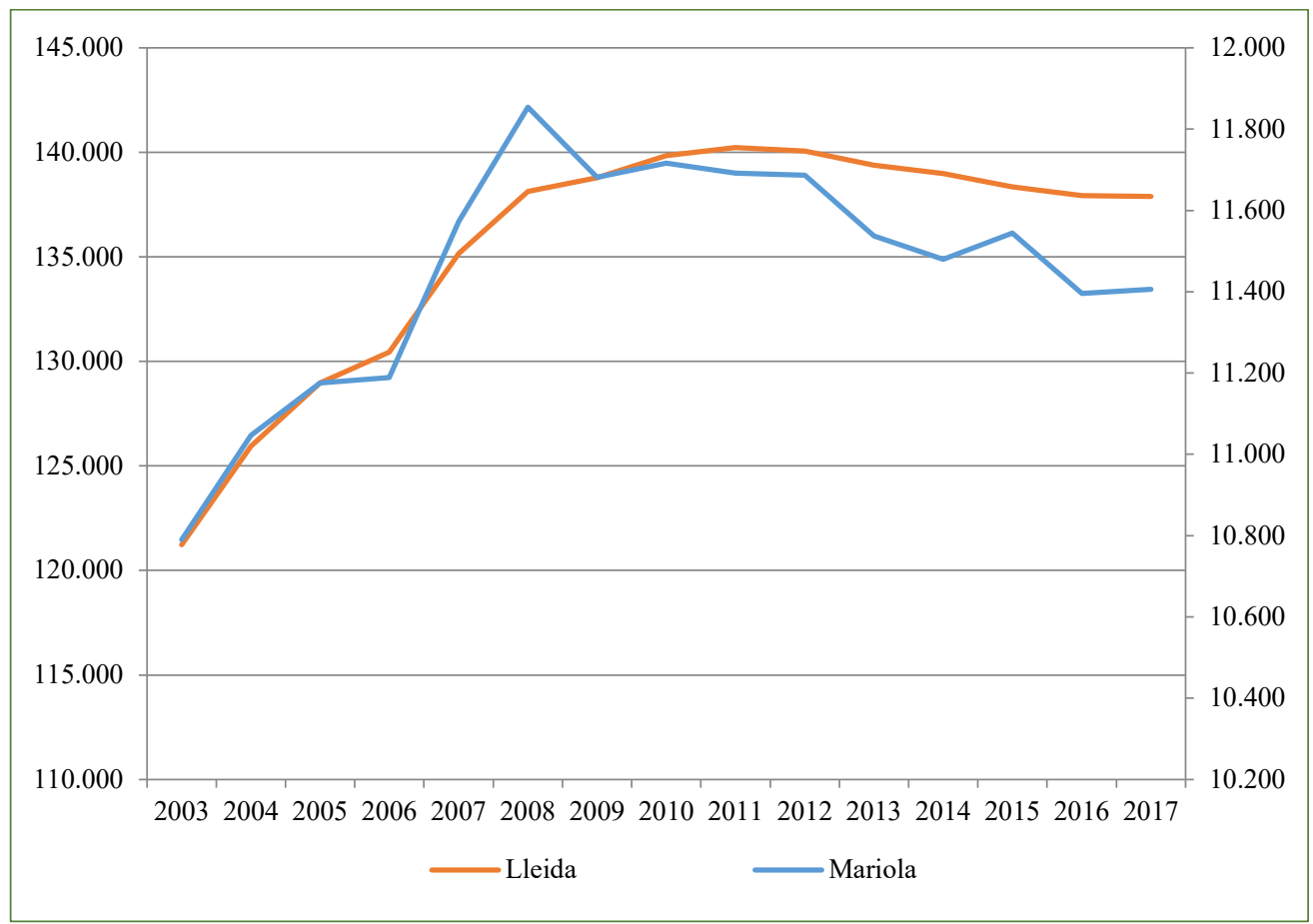

Figura 14. Evolución comparada de la población en Lleida y la Mariola (2003-2017)

Fuente: Datos de Población. La Paeria, el Ayuntamiento de Lleida. https://www.paeria.cat/cat/poblacio.asp.

Las consecuencias socioeconómicas fueron desastrosas para el barrio con el aumento del paro, el empeoramiento de las condiciones salariales y de trabajo y los desahucios (Paul y Solís 2019). La Mariola ha sido el barrio de la ciudad que ha acumulado más desahucios desde el impacto de la crisis (Gutiérrez y Vives 2018). Éste concentra, aún hoy, el parque de vivienda de compra más asequible de la ciudad, mientras que comparte con el Centro Histórico, los alquileres de precio más reducido. Según el portal inmobiliario Idealista ${ }^{8}$, el precio de la vivienda de compra en el área poligonal sería el más bajo de la ciudad. En el grupo Mariola, estos precios se mueven entre los 290 y los 310 euros el m², muchas en propiedad

7 Según el Padrón Municipal de Habitantes de 2018, la población extranjera empadronada en la Mariola responde a 67 nacionalidades diferentes destancando: Marruecos (24\%), Rumanía (18\%), Nigeria (5\%), Senegal (5\%), Mali (4,6\%) y Argelia (4,6\%).

8 Búsquedas realizadas el 10, 18 y 24 de agosto de 2020 en https://www.idealista.com 
de bancos y algunas okupadas (Paul y Solís 2019). Mientras que en los bloques Juan Carlos los precios, según la misma fuente, van de los 320 a los 350 euros el $\mathrm{m}^{2}$, siendo la media de la ciudad de 1.007 euros el $\mathrm{m} 2$ (todas las cifras para agosto de 2020).

Sin embargo, aquello que más caracteriza al barrio es la situación de pobreza crónica de muchas familias. Como muestran los datos, la pobreza parece ser más intensa en las secciones dónde se concentran los polígonos de vivienda (secciones 4.10 y 4.11) (Cuadro 2 y Figura 12). En estas secciones la media de la renta familiar disponible en el año 2016 es de 15.716 euros en la 4.10 y de 13.685 euros en la 4.11. En estas áreas entre un 34 y un $37 \%$ de la población vive en unidades de consumo cuyos ingresos no llegan a los 5.000 euros al año, y un 66-67\% por debajo de los 10.000 euros. Además, un 18\% de los ingresos dependen de pensiones de empleo y asistenciales (11\% en el conjunto del barrio que es un $6,2 \%$ en el conjunto de la ciudad), unas prestaciones asistenciales que, en muchos casos, se han cronificado o bien son de larga duración (Corona 2019).

Cuadro 2. Renta media familiar disponible e ingresos por unidad de consumo en las seccion
distrito de la Mariola (2016)
\begin{tabular}{|l|c|c|c|c|}
\hline & & $\begin{array}{c}\% \text { Población en unidad de consumo según } \\
\text { ingresos de la unidad }\end{array}$ \\
\hline Secciones de distrito (*) & $\begin{array}{c}\text { Renta media } \\
\text { familiar } \\
\text { disponible }\end{array}$ & $\begin{array}{c}\text { Menos de } \\
5.000 \text { euros }\end{array}$ & $\begin{array}{c}\text { Menos de } \\
7.500 \text { euros }\end{array}$ & $\begin{array}{c}\text { Menos de } \\
10.000 \text { euros }\end{array}$ \\
\hline Seccion 4.8 & 22.883 & 19,2 & 30,4 & 44,4 \\
\hline Sección 4.10 & 15.716 & 34,3 & 50,5 & 65,8 \\
\hline Sección 4.11 & 13.685 & 37,2 & 52,9 & 67,1 \\
\hline Sección 4.13 & 22.407 & 20,0 & 33,5 & 47,8 \\
\hline Sección 4.14 & 23.977 & 15,5 & 26,3 & 38,2 \\
\hline Sección 4.15 & 29.933 & 8,2 & 13,7 & 23,9 \\
\hline Sección 4.17 & 32.298 & 4,6 & 12,6 & 22,4 \\
\hline Barrio Mariola & 22.986 & 19,9 & 31,4 & 44,2 \\
\hline Municipio de Lleida & 30.713 & 11,1 & 19,6 & 30,3 \\
\hline
\end{tabular}

Fuente: Estadísticas experimentales, INE - Atlas de distribución de renta de los hogares, 2016,

https://www.ine.es/experimental/atlas/experimental_atlas.htm. Consultado en Julio 2019.

(*) La delimitación de las secciones de distrito del barrio pueden verse en la Figura 12

La pobreza ha ido en aumento desde la crisis de 2008 y estimamos que puede haber incrementado tras el impacto de la COVID-19, a juzgar por el aumento de peticiones de ayuda que relatan los servicios sociales y organismos del tercer sector que actúan en el barrio.

\section{Mala fama. La creciente estigmatización territorial del barrio}

A medida que el barrio va quedando integrado en la trama urbana, delimitado, eso sí, por las barreras que lo separan de las áreas de rentas medias al este, y medias-altas al norte, la denigración simbólica del mismo va en aumento. Aquí es cuando pasa a operar con mayor fuerza el estigma territorial. 
El estigma territorial es una narrativa negativa impuesta que funciona como una forma de poder y que sirve para reproducir las jerarquías sociales y espaciales existentes en un territorio en un momento dado, justificando así las situaciones de injusticia social (Tyler y Slater 2018). Esas desiguales relaciones de poder no solo se manifiestan en la producción externa del estigma por parte de las instituciones, medios de comunicación y ampliadas por las redes sociales, sino que también están presentes en las diferentes experiencias de vida de los residentes dentro del mismo barrio. Las respuestas al estigma son diferentes y van desde la alienación hasta la afirmación de la identidad. Otra respuesta posible es la lateralización que se produce cuando se culpa a otras personas residentes en el mismo barrio de las acciones que, se supone, alimentan el estigma.

Buena muestra del estigma con que cuenta el barrio es la figura del "Mariolero", que popularmente se atribuye en la ciudad a un varon que responde con actitudes chulescas y formas un tanto agresivas. La figura tiene un correspondiente femenino, la "Mariolera", que en su caso se refiere, además, a una mujer que viste de forma llamativa. Estas actitudes sirven a algunos habitantes, especialmente a la gente joven, como mecanismo de autoafirmación. Una juventud marcada por el estigma que es expulsada de los espacios públicos centrales de la ciudad, en los que es vista como intrusa, y por ello es relegada al uso intensivo de los espacios públicos de su barrio. El lugar que le corresponde.

El 24/02/2020, un grupo de jóvenes de la Mariola, todos hombres de entre 14 a 24 años, publicaba un video musical titulado "Mi barrio es" 9 . La letra, a ritmo de rap y mezcla de sonidos urbanos latinos, juega con muchos de los estereotipos desvalorizantes que se vuelcan sobre el mismo. El video, que utiliza como escenario el espacio público del área poligonal, pretende mostrar, según los artistas, que la Mariola no es un barrio marginal. El rap se convierte en una clara expresión de revuelta frente al estigma territorial que les oprime. Una revuelta en forma de rap que simbólicamente se construye a partir de lo que su barrio si es para ellos.

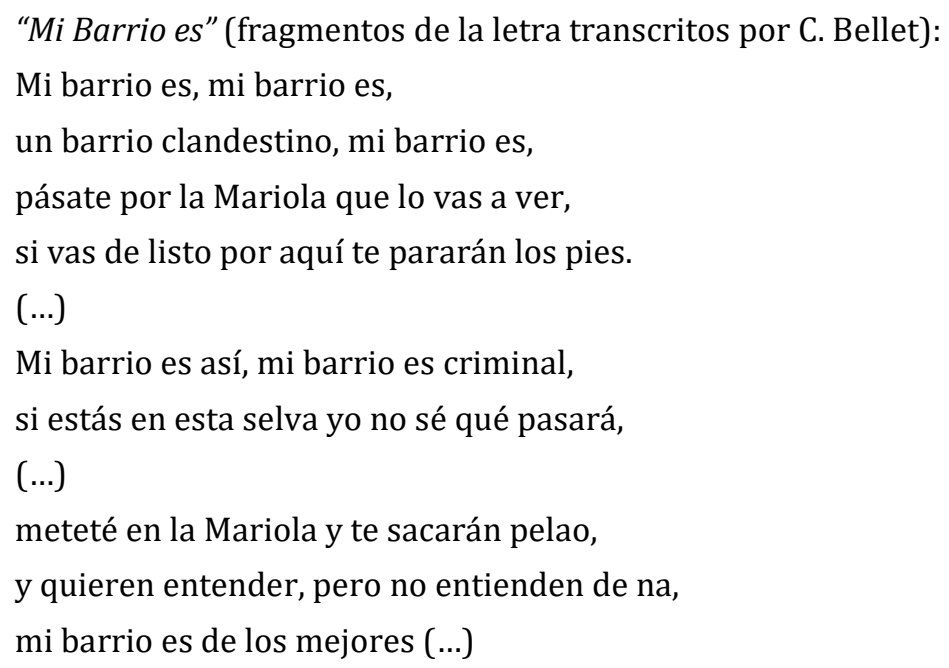

9 El proyecto musical es de Delasurandy, el Princy, el King, el Choco y JowRP, nombres artísticos de: Antonio Giménez, Antonio Griñán, Manuel Fernández, Pedro Giménez y Joel Ribas, a los que se une para interpretarlo: el Cubanito. Ver https://www.youtube.com/watch?v=wz4FIJv3rig. 
Y de los bloques un paquete podría yo explicar,

es el barrio donde nací, donde yo me he criao,

hay buena gente, pero también hay mucho que ha mamoneao,

pero eso no me preocupa primo, como en todos los laos

(...)

De mi barrio no me olvido pa mi es internacional,

y en la tele lo conocen como un barrio marginal.

(...)

nos pusieron en cuarentena, y ahora estamos en peligro de extinción,

(...)

nos criamos todos juntos, jugando en el callejón,

muchos hablan bla bla bla, muchos dicen bla bla bla,

no critiques lo que hago compa que lo vivo yo.

(...)

En el barrio lo gozamos los payos y los gitanos,

se trata de confianza, ¿qué pasó mi hermano?

(...)

Con la letra se viene a confrontar la vida en lo cotidiano a la vida extraordinaria que otras personas ajenas a esa realidad suponen se vive en esa "selva". Con los estereotipos negativos impuestos se juzga y estigmatiza a toda la población, sin conocer ("muchos hablan bla, bla, bla"), sin entender ("y quieren entender, pero no entienden de na") y denuncian la opresión y encierro a que son sometidos con esas imágenes y narrativas desvalorizantes ("nos pusieron en cuarentena, y ahora estamos en proceso de extinción"). Los jóvenes no niegan que puedan existir algunos problemas, "como en todos los lados" y, configuran una autoafirmación de su identidad ("nací y crecí aquí, no critiques lo que vivo, que lo vivo yo") y una respuesta emocional frente a lo que consideran que es una imagen que les denigra ("es un barrio internacional, y en la tele lo conocen como un barrio marginal").

Desde la crisis, y pese a un intento por parte de la administración local de controlar las noticias negativas que con frecuencia salían en los medios de comunicación, la aparición de informaciones estereotipadas se ha multiplicado e incluso saltado a medios de difusión nacional en los últimos años. Droga, conflictos vecinales, delincuencia, deterioro y degradación de la vivienda y del espacio público, okupaciones conflictivas, entre otras problemáticas, se presentan en los medios de forma sensacionalista. Uno de los más recientes es el reportaje emitido por TVE el 15/03/2019: "Un barrio en derribo". El reportaje desde el principio naturaliza la pobreza y las situaciones de exclusión del barrio: "Todas las ciudades tienen una bolsa de pobreza y marginación. Lleida tiene la Mariola, un barrio que corre el riesgo de convertirse en un gueto (TVE, 15/03/2019 - "Un barrio en derribo") ${ }^{10}$.

10 Ver https://www.rtve.es/alacarta/videos/repor/repor-barrio-derribo/5070681/ 
La sensación de pérdida de control, resultante de la inestabilidad crónica y acumulativa $^{11}$ de los problemas que concentra el área desde los años novena, tiene un punto de inflexión que podemos situar a mediados de la década de los 2000 , antes incluso de la llegada de la crisis de 2008. El 2/02/2005 se produce una explosión de gas y posterior incendio en una vivienda de la calle Júpiter, en el grupo Mariola. Como consecuencia de la explosión mueren tres personas y otras dos resultan heridas, ocho viviendas del bloque quedan en ruinas y el edificio debe ser demolido (Fig. 15). La explosión pone al descubierto las malas condiciones en las que se encuentran algunas viviendas, las instalaciones y los edificios, a la vez que descubre al resto de la ciudadanía, las difíciles condiciones de vida de una población entre la que las situaciones de vulnerabilidad y extrema pobreza son frecuentes, especialmente en el área poligonal más antigua.

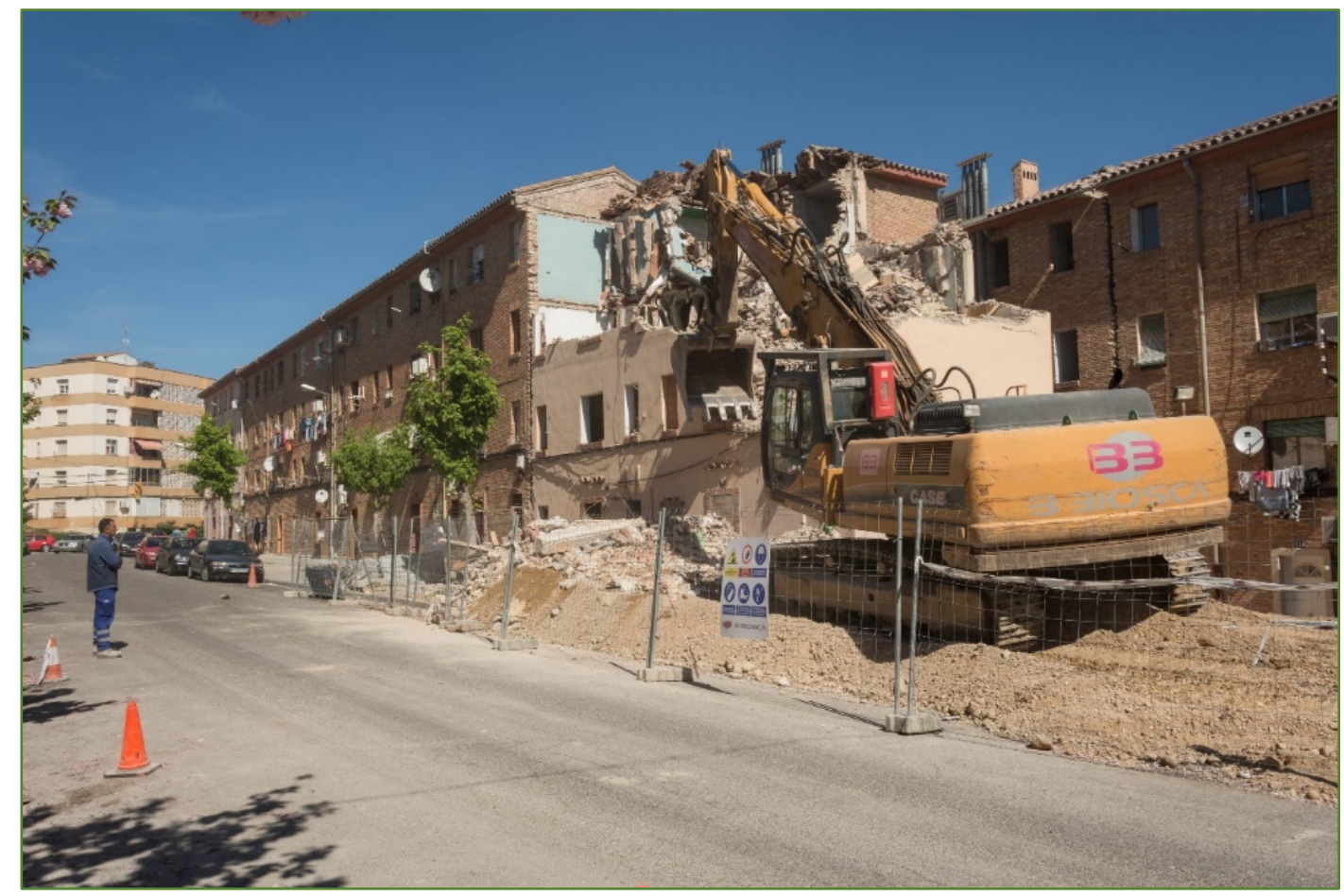

Figura 15. El derrumbe del bloque E de grupo Mariola afectado por una explosión de gas el 02/02/2005. Fuente: Sección de Notícias de la página web de La Paeria.

La explosión se produce justo cuando se estaba iniciando el Pla de barris de la Mariola que fue presentado a concurso en la primera edición del programa autonómico en el despliegue de la Llei 2/2004 de millora de barris, àrees urbanes i vil·les que requerían de atención especial por sus condiciones ${ }^{12}$. El proyecto para la Mariola se inicia en 2004 y

11 Atkinson y Kintrea apuntan, al respecto, que cuanto más grandes y duraderos son los problemas de estas áreas desfavorecidas, mas fuertes y acumulativos devienen los impactos, dando lugar a la huida de los más pudientes y a la pérdida gradual de control que conlleva la inestabilidad crónica (Atkinson y Kintrea 2011).

12 Resulta sintomático el hecho que el barrio fuera elegido ya, en la primera convocatoria del programa Pla de Barris, señalandolo como el barrio con más problemás de la ciudad. 
finaliza en 2011 y supone una importante inversión de 11,09 millones de euros en total, después de décadas de escasas intervenciones (públicas y privadas).

La inversión introduce substanciales mejoras en el espacio público (instalación de juegos infantiles, reurbanización de algunas calles, supresión de barreras arquitectónicas, ampliación de aceras y acondicionamiento de zonas verdes, entre otras) y aporta equipamientos necesarios para el barrio (ludoteca y guardería infantil). Pero poco incide en una de las problemáticas más acuciantes del mismo: las deficientes condiciones de habitabilidad de una parte importante del parque de viviendas. Por el tipo de programa propuesto, no puede actuarse en la escala individual de la vivienda, aún y con ello sí se procede de forma paralela a través de ADIGSA, a la reparación y renovación de algunos elementos comunes de los edificios como, por ejemplo, la instalación de 20 ascensores o la reparación de fachadas en algunos grupos (Gutiérrez y Paul 2011).

Sin embargo, una parte del grueso de la inversión (2,5 millones) va a la reurbanización de una Rambla perimetral que parece dirigirse a la solución de los problemas de tráfico que provocan dos equipamientos comerciales cercanos (Carrefour-Unipreus). Y otra parte importante del prespuesto se dirige a la construcción de un equipamiento cultural situado en la meseta de Gardeny (Museo de la Ciencia, el Clima y el Medio Ambiente) que tampoco llega a terminarse y que poco tiene que ver con las necesidades más acuciantes de las vecinas y vecinos del barrio.

Se consolidan también una serie de equipamientos cercanos a los bloques Juan Carlos (Centro de Asistencia Primaria, Escuela de Formación de Adultos, entre otros) que, aunque contribuyen a dar un servicio de proximidad, terminan por reforzar la barrera este del barrio que transcurre paralela al eje Passeig de Ronda (Fig.12). Los nuevos equipamientos generan bastante flujo de población procedente de barrios vecinos, sin embargo, las personas usuarias de los mismos no van más allá de los equipamientos quedándose pues a las puertas de la Mariola. No hay en la zona equipamiento alguno, servicio o hito que genere centralidad ni sea un referente urbano, más allá del mismo Centro de Asistencia Primaria. Si a ello añadimos los discursos e imágenes estigmatizantes y desvalorizantes, entendemos que sea no tan sólo un barrio desconocido (un área en blanco en los mapas mentales de la población), si no, sobre todo, un barrio evitado, al que no se debe ir.

En 2005, se establece el Consorcio entre la Paeria (Ayuntamiento de Lleida) y la Universitat de Lleida para la consolidación del Parque Científico y Tecnológico Agroalimentario (PCiTAL) que, con fondos FEDER, se ubica en las reformadas instalaciones exmilitares de la meseta de Gardeny. El acceso a las mismas se realiza a través del barrio de la Mariola. Justo en el acceso a las instalaciones de la meseta, al oeste de la Mariola y delante del grupo Gaspar de Portolá, la promotora Acciona Inmobiliaria construye, entre 2006 y 2009, una nueva promoción residencial dirigida a rentas medias (Residencial Alosa en la Fig. 12). Se trata de 417 viviendas que se disponen en varios edificios. Los edificios dan claramente la espalda al barrio del que tratan de aislarse orientado sus accesos hacia a Gardeny y vallando el perímetro. De nuevo, el recurso de la barrera de equipamientos (Club de Petanca y Guardería Pública Infantil, Instituto de Enseñanza Secundaria Templers) separa las nuevas promociones de los bloques Gaspar de Portolá y Mariola (barrera oeste en Fig.12). 
Las viviendas han tenido, y tienen aún, muchas dificultades de venta estando todavía muchas de ellas vacías. El precio de las mismas va de los 1.450 euros el $\mathrm{m}^{2}$, las viviendas más cercanas al área polígonal que son también las más sencillas, a los 2.022 euros $\mathrm{m}^{2}$, las viviendas de los edificios vallados y que cuentan con una piscina comunitaria. Las y los nuevos inquilinos crearon, en 2012, la Asociación Vecinal Turó de Gardeny después de expresar, de forma reiterada, su voluntad de segregarse de la Asociación de la Mariola, barrio del que dicen no formar parte.

Así, la presión y la opresión urbanística del barrio aumenta con la construcción del Parque Tecnológico de Gardeny, la nueva promoción Residencial Alosa y la definitiva consolidación de las barreras al este (rentas medias del ensanche) y al norte (rentas medias altas de Joc de la Bola) (Fig.12).

En paralelo crece la presión mediática estigmatizante de la que da buena muestra el video "Mala fama", un documental realizado en 2015 por estudiantes de Periodismo y Comunicación de la Universitat de Lleida ${ }^{13}$.

A la par aumentan las quejas vecinales y empiezan a producirse acciones de protesta y movilización social por el empeoramiento de las condiciones de vida en el barrio. Fruto de estas acciones, surge en 2016 "Mariola en moviment" que pondrá en evidencia desde entonces la vulnerabilidad social y los problemas habitacionales en el barrio.

Delante de las protestas vecinales el consistorio anuncia, en septiembre de 2018, el Plan Mariola 20.000, un plan de regeneración urbanística sobre el grupo Mariola que finalmente decide transformarse en un Plan de Regeneración Integral. El Plan tenía la intención de derribar los edificios más viejos e insalubres del grupo Mariola para hacer nuevos bloques y dinamizar socioeconómicamente el barrio a través de procesos participativos ${ }^{14}$. Problemas presupuestarios y cambios en el gobierno local paralizaron un proyecto que sólo había avanzado en la fase de diagnóstico. La crisis habitacional que se desprende de esos primeros estudios es uno de los puntos más destacados. Como ejemplo, de las 508 viviendas del grupo Mariola: 238 están en situación regular, 204 se encontraban vacías (muchas en manos de bancos) y 66 en situación de ocupación irregular (Paul y Solís 2019). El mal estado de las viviendas y la falta de recursos de los inquilinos explican también la alta rotación de sus ocupantes: el 30\% de las familias que vivían en el grupo la Mariola en febrero de 2019 hacía menos de 5 años que habían llegado al barrio. Respecto a las dificultades de tipo socioeconómico, resaltan las elevadas tasas de desempleo de larga duración y el significativo desempleo juvenil que se sitúa entre el 60-70\%. El estudio destaca además el absentismo, el fracaso escolar y el abandono prematuro de los estudios entre la población en edad de escolarización obligatoria (Gutiérrez y Paul 2011).

Durante la crisis desatada por la COVID-19 el barrio ha sido uno de los más afectados directamente por el avance y el volumen de los casos detectados, junto a otros barrios

13 Ver https://www.youtube.com/watch?v=AFU_E1mRS60\&t=170s .

14 El plan pretendía, en el plazo de 8 a 10 años, construir nuevas viviendas para los vecinos, instalaciones, espacios para comercio cotidiano y habilitar nuevas zonas verdes. Actualmente, el Plan se encuentra paralizado tras el cambio político que se produce en el consistorio local tras las últimas elecciones de 2019. 
obreros densos con peores condiciones de habitabilidad, trabajos precarios y con volúmenes notables de población vulnerable (Centro Histórico y Noguerola).

\section{Conclusiones}

La Mariola, como tantos otros, es un barrio de polígonos de vivienda construido en los márgenes de la ciudad, dónde las condiciones de marginalidad han sido producidas y reproducidas históricamente frente a la acción /inacción de las instituciones públicas.

Es un espacio urbano en el que se han combinado tres mecanismos para el manejo de la pobreza: los procesos de segregación espacial (concentración); la producción de barreras físicas y simbólicas que delimitan y confinan a la población (contención); y la estigmatización territorial (neutralización). La fuerza y el despliegue de los mecanismos coexisten y se refuerzan, aunque, como hemos visto, su protagonismo va cambiando a lo largo del tiempo.

A partir de los años noventa, el barrio, en una localización inicial periférica, queda integrado en el tejido del núcleo urbano central al desarrollarse un barrio de rentas medias al este y un barrio de rentas medias-altas al norte. Las altas expectativas de transformación y captación de plusvalías urbanísticas, tras fuertes inversiones inmediatas, lo reposicionan en el conjunto de la ciudad y, tras la segregación inicial, pasan a operar otros mecanismos espaciales: las barreras y el estigma, para controlar y contener la marginalidad. Com se ha argumentado en el texto estos mecanismos son importantes en el caso de ciudades medias con estructuras relativamente continuas y compactas. La presencia de barreras físicas y simbólicas externas que lo segregan y aíslan del resto de la ciudad, e internas (los diferentes grupos poligonales, por ejemplo) dan como resultado un barrio segregado y fragmentado en su interior.

Con el artículo, pretendemos también destacar el papel que juegan las estructuras simbólicas en la producción de la desigualdad y la marginalidad en las ciudades. La segregación residencial, por si misma, no logra capturar el nivel de segregación que las personas que viven en estos barrios experimentan en su vida cotidiana. Por ello, creemos que deberíamos de ser capaces de complementar los estudios de segregación residencial con el análisis de otros tipos de segregación (educativa, sanitaria, laboral, lúdica, entre otras), junto a las narrativas e imagenes desvalorizantes que inciden también en la vida cotidiana de las personas.

En ese sentido, sería necesario que las políticas públicas se dirigieran no sólo a la reducción de las carencias materiales, sino también a la disminución de la presión ejercida por la dominación simbólica del estigma territorial y otras imágenes desvalorizantes. Las políticas públicas tratan con demasiada frecuencia sólo los síntomas (degradación del entorno, ocupaciones, inseguridad), pero obvian sus causas (desigualdad, falta de recursos, habitabilidad, estilos de vida diferenciados, etc.). Y por todo ello, no pueden evitar que se perpetúen, cronifiquen e incluso amplíen las situaciones de desigualdad y marginalidad.

Además, al dirigir su punto de mira a aquello que sucede dentro del barrio, al que se culpabiliza de la situación, quedan ocultas las cuestiones estructurales y la creciente desigualdad entre las diferentes partes/barrios de la ciudad. La segregación, la desigualdad y el estigma no pueden resolverse exclusivamente con políticas en los barrios 
desfavorecidos. Sólo si logramos abordar las cuestiones estructurales que causan estas problemáticas a escala urbana/metropolitana avanzaremos en su posible solución.

\section{Bibliografía}

Aguayo, Xavier. 2018. La immigració a la ciutat de Lleida durant el segle XX: el punt d'inflexió del franquisme. Estudi d'un impacte demogràfic i urbanístic sense precedents. Tesis doctoral, Universitat Autònoma de Barcelona. https://www.tdx.cat/handle/10803/650413

Aguilar, Laura y Bellet, Carme. 2014. "La ciudad evitada y omitida: el Centro Histórico de Lleida, de vacío a espacio marginal". En Territorios inconclusos y sociedades rotas, XII Coloquio del Grupo de Geografía Urbana (AGE), editado por Dolores Brandis, Casilda Cabrerizo y Elia Canosa (et al.). Madrid y Castilla La Mancha.

Alguacil Gómez, Julio. 2006. "Barrios desfavorecidos: diagnóstico de la situación española". En V Informe FUHEM de políticas sociales: La exclusión social y el estado del bienestar en España, editado por Fernando Vidal Fernández, 155-168. Madrid: FUHEM.

Alguacil, Julio; Camacho, Javier y Hernández Aja, Agustín. 2014. "La vulnerabilidad urbana en España. Identificación y evolución de los barrios vulnerables". Empiria. Revista de Metodología de Ciencias Sociales, 27: 73-94. https://doi.org/10.5944/empiria.27.2014.1086

Atkinson, Rowland y Kintrea, Keith. 2001. "Disentangling area effects: Evidence from deprived and non-deprived neighbourhoods". Urban Studies, 38(12): 2277-2298. https://doi.org/10.1080/00420980120087162

Ávila, Débora y García, Sergio. 2015 “Entre el riesgo y la emergencia: la nueva protección social en el marco del dispositivo securitario neoliberal". En Enclaves de riesgo: gobierno neoliberal, desigualdad y control social, editado por Débora Ávila y Sergio García (Observatorio Metropolitano de Madrid), 83-104. Madrid: Traficantes de sueños.

Barrull, Jaume; Mir, Conxita y Jarne, Antonieta. 2003. De la Restauració al Franquisme Història de Lleida. Història de Lleida, vol. 8. Lleida: Pagès editors.

Beck, Ulrich. 2008. La sociedad del riesgo mundial. Hacia una nueva modernidad. Madrid: Paidós Surcos.

Bellet Sanfeliu, Carme. 1995. Activitat immobiliària i polítiques urbanes dels anys vuitanta a les ciutats mitjanes catalanes. El cas de la ciutat de Lleida. Tesis doctoral. Universitat de Lleida, https://www.tdx.cat/handle/10803/8189

Bellet Sanfeliu, Carme. 2007. "Los espacios residenciales de tipo privativo y la construcción de la nueva ciudad". Scripta Nova: Revista electrónica de geografía y ciencias sociales, 11, (245:vol extra - IX Coloquio Internacional de Geocrítica). http://www.ub.edu/geocrit/9porto/bellet.htm

Bellet, Carme y Llop Josep M. 2004. "Miradas a otros espacios urbanos: las ciudades intermedias". Scripta Nova. Revista electrónica de geografía y ciencias sociales, 8 (165). http://www.ub.es/geocrit/sn/sn-165.htm. 
Bellet, Carme y Modol, Josep R. 2006. "La Mariola. De polígonos de vivienda pública a barrio urbano". En Los procesos postfordistas. Actas del VIII Coloquio y jornadas de campo de Geografia Urbana, editado por Artigues, Antoni.; Bauzà, Alicia; Blázquez, Macià; Murray, Ivan y Rullán, Onofre, 47-70. Palma: Universitat de les Illes Balears.

Capel, Horacio. 1998. "Una geografía para el siglo XXI”. Scripta Nova. Revista Electrónica de Geografía y Ciencias Sociales, 19. http://www.ub.es/geocrit/sn-19.htm.

Castel, Robert. 1995. "De la exclusión como estado a la vulnerabilidad como proceso". Archipiélago, 21:27-36.

Corona, E. 2019 Pla Integral Mariola. Diagnòstic i estratègia inicial. Lleida: La Paeria (Documento inédito).

Delgado, Manuel. 2014. "El miedo al gueto". En II Seminario Atlántico de pensamiento. https://issuu.com/seminarioatlanticodepensamiento/docs/manuel_delgado

García, Sergio y Ávila. Débora (Observatorio Metropolitano de Madrid) (Ed.). 2015. Enclaves de riesgo: gobierno neoliberal, desigualdad y control social. Madrid: Traficantes de sueños.

García-Herrera, Luz Marina. 2018. "Mercantilización del espacio urbano bajo la lógica neoliberal: gentrificación y redefinición de los espacios públicos en España”. En Naturaleza, territorio y ciudad en un mundo global, editado por AAVV, 858-877. Madrid: Universidad Autónoma de Madrid \& AGE

Garriga, Albert y Rueda, Agustín. 2015. Mala fama: Mariola i blocs Joan Carles . Documental realizado por estudiantes de Periodismo y Comunicación Audiovisual de la Universitat de Lleida (44 minutos). https://www.youtube.com/watch?v=AFU_E1mRS60\&t=170s

Gutiérrez, Aaron y Paul, Daniel. 2011. Memòria final i de continuïtat del projecte del Pla de Millora del Barri de la Mariola de Lleida. Pla de Millora de Barri, Empresa Municipal d'Urbanisme - La Paeria. http://emu.paeria.es/files/AvaluacioFinalMAriola.pdf

Gutiérrez, Aaron y Vives, Sònia. 2018. “Acumulación de viviendas por parte de los bancos a través de los desahucios: geografía de la desposesión de vivienda en Cataluña". Eure, 44, (132): 5-26. https://scielo.conicyt.cl/pdf/eure/v44n132/0250-7161-eure-44132-0005.pdf

Lehman-Frisch, Soni. 2009. "La ségrégation: une injustice spatiale? Questions de recherche". Annales de Géographie, 2009/1 (665-666): 94-115. Doi: 10.3917/ag.665.0094

López Sánchez, Pere. 2015. “Acotar los espacios. Los márgenes de las periferias”. En Horacio Capel. Geógrafo, editado por Luis Urteaga y Vicente Casals, 123-142. Barcelona: Publicacions i edicions de la Universitat de Barcelona, Col. Homenatges.

Marcuse, Peter. 1989. "Dual city: A muddy metaphor for a quartered city". International Journal of Urban and Regional Research, 73:697-708. https://doi.org/10.1111/j.14682427.1989.tb00142.x

Massey, Douglas S. y Fischer, Mary J. 2000. "How segregation concentrates poverty". Ethnic and Racial Studies, 23(4): 670-691. https://doi.org/10.1080/01419870050033676 
Méndez Gutiérrez del Valle, Ricardo. 2018. La telaraña financiera. Una Geografía de la financiarización y su crisis. Santiago de Chile: RiL editores, Instituto de Geografía de la Pontificia Universidad Católica de Chile.

Paul, Daniel y Solis, Juan Manuel. 2019. “Informe: Procés participatiu Mariola 20.000”. Pla Mariola 20.000. Lleida: La Paeria. Documento inédito

Real Academia Española. 2019. Diccionario de la Lengua Española, Actualización de 2019, https://dle.rae.es/barrio

Sassen, Saskia. 2015. Expulsiones, brutalidad y complejidad en la economía global. Buenos Aires y Madrid: Ediciones Katz.

Soja, Edward W. 2014. En busca de la justicia espacial. València: Tirant Humanitats

Solis, Juan Manuel. 2017. La Mariola desde dentro y desde fuera. Lleida: Edicions de la Universitat de Lleida. Col.lecció Espai/temps 71.

Subirats, Joan; Riba, Clara; Giménez, Laura; Obradors, Anna; Giménez, Maria; Queralt, Didac; Bottos, Patricio y Rappoport, Ana. 2004. Pobreza y exclusión social. Un análisis de la realidad española y europea. Barcelona: Fundación la Caixa.

Tyler, Imogen y Slater, Tom. 2018. "Rethinking the sociology of stigma". The Sociological Review, 66 (4): 721-743. https://doi.org/10.1177/0038026118777425

Van Kempen, Ronald. 2007. "Divided cities in the 21st century: challenging the importance of globalisation". Journal of Housing and the Built Environment, 22 (1):13-31. DOI 10.1007/S10901-006-9064-3

Vilagrasa, Joan. 1990. Creixement urbà i agents de la producció de l'espai: el cas de la ciutat de Lleida, 1940-1980. Barcelona: Institut Cartogràfic de Catalunya.

Vilagrasa, Joan. 2002. Vivienda y promoción inmobiliaria en España. Lleida: Ed. de la Universitat de Lleida, Col. Espai/Temps.

Vilagrasa, Joan. 2003. Finals de segle XX. Història de Lleida, vol. 9. Lleida: Pagès editors.

Wacquant, Loïc. 2007a. Dos caras de un gueto. Madrid: Siglo XXI.

Wacquant, Loïc. 2007b. Los condenados de la ciudad. Gueto, periferias y Estado. Madrid: Siglo XXI.

(C) Copyright Carme Bellet, 2021

(C) Copyright: Scripta Nova, 2021.

Ficha bibliográfica:

BELLET, Carme. La producción de un barrio desfavorecido en los márgenes de una ciudad media: La Mariola (Lleida, Cat-Esp). Scripta Nova. Revista Electrónica de Geografía y Ciencias Sociales. Barcelona: Universitat de Barcelona, vol. 25, Núm. 1 (2021), p. 75-103 [ISSN: 1138-9788]

DOI: $10.1344 / \mathrm{sn} 2021.25 .32421$ 